\begin{tabular}{|l|l|}
\hline El proletariado minero en Bolivia & Titulo \\
\hline Zavaleta Mercado, René - Autor/a; & Autor(es) \\
\hline La autodeterminación de las masas & En: \\
\hline Bogotá & Lugar \\
\hline $\begin{array}{l}\text { Siglo del Hombre Editores } \\
\text { CLACSO }\end{array}$ & Editorial/Editor \\
\hline 2009 & Fecha \\
\hline $\begin{array}{l}\text { MNR - Movimiento Nacionalista Revolucionario; Clase obrera; Burguesía; } \\
\text { Proletariado; Estado; Clases sociales; Política; Teoría de la dependencia; } \\
\text { Nacionalismo; Bolivia; }\end{array}$ & Colección \\
\hline Capítulo de Libro & Temas \\
\hline "http://biblioteca.lacso.edu.ar/lacso/se/20160314045732/11prole.pdr" & Tipo de documento \\
\hline $\begin{array}{l}\text { Reconocimiento-No Comercial-Sin Derivadas CC BY-NC-ND } \\
\text { http://creativecommons.org/licenses/by-nc-nd/2.0/deed.es }\end{array}$ & URL \\
\hline
\end{tabular}

Segui buscando en la Red de Bibliotecas Virtuales de CLACSO http://biblioteca.clacso.edu.ar

Consejo Latinoamericano de Ciencias Sociales (CLACSO)

Conselho Latino-americano de Ciências Sociais (CLACSO)

Latin American Council of Social Sciences (CLACSO)

www.clacso.edu.ar

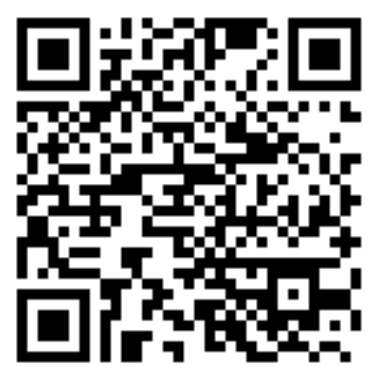




\section{EL PROLETARIADO MINERO EN BOLIVIA ${ }^{1}$}

\section{INTRODUCCIÓN}

El grupo humano que interesa estudiar en este trabajo es el de los mineros bolivianos, grupo que constituye sin duda, por su decisiva colocación en un sector básico de la producción boliviana, como es la minería, por el tipo de su actuación grupal (fruto a su turno de su considerable homogeneidad) y por sus particularidades como tipo de clase obrera misma, el sector más interesante entre todos los del proletariado boliviano.

Es imposible, sin embargo, estudiar este sector como sector mismo o sector en sí mismo, es decir, sólo en su contorno aislado. Su origen lo hace arrancar de otras clases sociales y es, en este sentido, un desprendimiento; pero, además, se define con relación a otras clases sociales y, por otra parte, en ningún caso como en éste el fenómeno de irradiación de clase o aculturación de clase cobra una trascendencia tan grande y tan tangible.

1 Texto extraído de Revista Mexicana de Sociología, año XI, vol. XV, № 2, México, 1978 , pp. 517-559. Este texto fue presentado originalmente en el Seminario sobre Sindicalismo y Desarrollo Económico realizado en San Carlos de Bariloche (Argentina), con el auspicio del Instituto Internacional de Estudios Laborales (IIEL-Ginebra) y la hospitalidad de la Fundación Bariloche, en diciembre de 1974. 
Un estudio tal, tanto por las disponibilidades de tiempo como por la imposibilidad de hacer investigaciones de campo, no puede sino detenerse en su fase descriptiva, pero ya los elementos de juicio que surgen de los hechos más notorios ofrecen un cuadro de referencias revelador. En este caso, prescindimos de las fases de formación de la clase, es decir, de su pertinencia histórico-cronológica, y nos atendemos a sus resultados históricos más relevantes. Con todo, algunos son en sí mismos atractivos. Después de todo, la tradición de la minería en Bolivia es anterior a los mismos españoles y, sin duda, en la explotación de la plata, dejando atrás la mita colonial, creó a su turno alguna forma de proletariado, especialmente en el último tercio del siglo XIX. No hay noticias organizadas acerca de presencia social de dichos núcleos de trabajadores, y no se puede saber bien por qué los nuevos mineros, los que estudiamos, que son los de la minería del siglo XX, principalmente la del estaño, se desentienden de toda esa presunta tradición y formulan su modalidad de clase en términos totalmente diferentes. Eso mismo, empero, no es lo resolutivo de la cuestión. En los hechos, la minería del estaño crea un núcleo pequeño pero bien perfilado. Desde su constitución, en los principios del siglo XX, hasta su aparición orgánica en la política, en la década de los cuarenta, hasta el momento en que prácticamente "produce" la revolución democrática de 1952, hay un largo trecho. Pero, para decirlo en términos sencillos, es en torno a la resistencia y la rebelión del proletariado minero que se reconstituye la sociedad boliviana en su conjunto.

Cómo esta clase logra su propia unidad interna y después cómo unifica tras de sí a todo el proletariado del país, arrastrando además al campesinado y a grandes porciones de la pequeña burguesía urbana, cómo impide el éxito de los propios mecanismos de mediatización del Estado al que da lugar y cómo en determinado momento está ya en condiciones de lanzar su propio proyecto estatal, cuáles son los resortes ideológicos con los que se impulsan estas tareas, tales son algunas de las cuestiones que tratamos de esbozar en estos apuntes. 
Es cierto que un trabajo empírico de todos estos problemas podría ofrecernos matices de los hechos o explicaciones a zonas no descubiertas de los hechos; pero la aparición misma de la clase en su fenómeno histórico es algo que ninguna comprobación empírica podría desmentir. Las clases no están siempre a la luz de la misma manera y en todos los momentos; durante largas etapas parecen replegadas, desconocidas, enterradas. Por otra parte, cuando hablamos de conocimiento o estudio de la clase hablamos, en primer lugar, del conocimiento de la clase por sí misma. De aquí proviene la importancia del estudio de la gran crisis política de 1952 para saber de dónde vino el proletariado, en qué consistía, qué podía y qué no podría. Éste es el método que se ha usado en Bolivia para estudiar este asunto, y tiene una implicación más general.

En efecto, el obstáculo sistemático de una sociedad atrasada radica en un momento esencial: su propio conjunto de determinaciones la hace incapaz de volver sobre sí misma, las propias evasiones y fragmentaciones cognoscitivas aquí son como una prolongación del desconocimiento de esas determinaciones, las compensaciones son el principio y el fin de todos sus modos de conciencia y, en general, se puede decir que es una sociedad que carece de capacidad de autoconocimiento, que no tiene los datos más pobres de base como para describirse. Con relación a su propio ojo teórico, esta sociedad se vuelve un noúmeno.

Puesto que los fenómenos sociales no se muestran sino como objetos erráticos de un sujeto que o no está ahí o no sabe que le pertenece el papel de sujeto para construir esa unidad de acción que es la confusión sujeto-objeto, puesto que los hechos no son representables ni delimitables y que, por consiguiente, no se puede elaborar el continuum concreto / representación abstracta / concreto de pensamiento que Marx definió como su método sociológico, todo conduce aquí, por consiguiente, a que lo que se pueda producir de inteligencia social se entregue a la construcción de un movimiento voluntarista. La colocación misma del sujeto sociológico intelectual está dada de un modo que está 
hecho no para conocer sino para no conocer, y hasta su propia actividad no es sino una acentuación de la distorsión general. No en balde, en la historia de las ideas sociales latinoamericanas, sus momentos más lúcidos son aquellos en los que su inteligencia se subleva contra el vasallaje consagrado de las ideas europeas, en un arranque autónomo que sería bárbaro si no conllevara el supuesto de que la importancia de tales supuestos que se proclamaban universales, como toda idea ocasional en el decurso del país central, acumulaban las imposibilidades de autoconocimiento y retorcían aún más los márgenes del propio razonamiento local.

A estas alturas es totalmente obvio que la principal contribución sociológica del movimiento obrero boliviano es el estudio de la crisis nacional general como método de conocimiento de una formación económico-social atrasada. Es seguro que los ideólogos de la clase obrera de ese momento, es decir, los portadores de la fusión entre la colocación estructural de la clase y su instante de revelación, tenían ya adquirido el concepto de que el marxismo como tal se refiere al análisis de las situaciones concretas; pero, por cierto, es difícil que conocieran o tuvieran en mente (conocimiento actual) lo que es el análisis de la totalidad a partir de la intensificación analítica del "nudo principal de una situación", es decir, de su aislamiento como categoría sintética de conocimiento de la totalidad social. Fue el movimiento de la formación económico-social lo que pidió el uso de su método, que no estaba conscientemente insertado en nadie.

Ahora bien, la crisis es a la vez el desgarramiento y la universalidad. Las clases inertes o receptoras se escinden aquí de la unidad autoritaria, la sociedad se hunde hasta el tope mismo de sus relaciones de producción presentadas de una manera atrozmente desnuda a partir del hundimiento de su superestructura y, por consiguiente, la crisis alcanza a la universalidad de los sujetos del ámbito de la crisis, es decir, a todo el alcance político-práctico de la sociedad, y no solamente a los grupos integrados a los indicadores por cierto volátiles que se usan comúnmente para medir la participación. Lo mismo que los individuos con relación a su 
acontecimiento culminante, que es su muerte natural, hecho tan flagrante frente al cual no pueden ser sino lo que son, las sociedades no asisten a su detraimiento como fases sino como lo que realmente son, y aquí se olvida su circunstancia de poder, la verticalidad de sus mitos, la inercia de su autoridad. Lo único que actúa es la fuerza material de sus clases, estén o no contenidas en la expresión política de su estatuto previo. Lo que aparece es la desnudez de las clases y no la mediatización de las clases (la crisis es la crisis de la mediación). Las clases, pues, aprenden las dimensiones de su poder y la eficiencia de su poder no desde los análisis previos, que son todos incompletos o presuntivos o totalmente inexistentes, como consecuencia de aquellos límites cognoscitivos de este tipo de sociedades en el momento de su quietud, sino a partir de su práctica; aquello que pueden y aquello que no pueden es lo que son. Aislamos la crisis y a partir de esta condensación o examen pragmático podemos recién evaluar, en lo que es una nueva aplicación de la inversión del método histórico que consiste en la categoría de la serie temporal, también presente ya en Marx, el recorrido previo de las clases y la caracterización de los modos de producción que entran en situación de catástrofe; es decir, sólo lo posterior explica y contiene a lo anterior. La crisis, por tanto, es el movimiento de estas sociedades y quizá de las sociedades en general. De aquí se derivan las cuestiones del momento del conocimiento social, es decir, de la súbita capacitación del sujeto, que es la clase, para conocer lo que antes le estaba vedado, de la presentación "llena" de la sociedad, que antes no se presentaba sino en su parte legalmente aceptada, pero que sólo ahora se presenta como todo su número y, por último, la crisis como escuela, porque sólo la clase que se ha preparado puede en ese momento conocer lo que le ocurre. De otra manera, como es el caso, el conocimiento será posterior a la perspectiva objetiva del poder. Y como el poder es, en último término, la unidad entre la posibilidad objetiva y la conciencia subjetiva de esa perspectiva, por tanto la crisis se convierte en una escuela. La clase ha avanzado mucho, pero ha perdido la ocasión. 


\section{LA MATRIZ DEL 52}

Tomamos, pues, como punto de referencia la crisis nacional general que se produce en Bolivia en torno a la insurrección popular del 9 de abril de 1952.

En ese momento se reconstituyen las clases, cada una de ellas según el carácter de su necesidad, se reformula la totalidad del poder del país y se lo concentra en una medida en que no tiene antecedentes en toda la vida republicana. Se está entonces ante una página en blanco. Como no hay ejército, por ejemplo, se puede decidir si debe o no existir uno, y cuál es la forma que debe adoptar. Pues las influencias regionales clásicas no pesan en el nuevo poder, se puede resolver dónde se intensifican los esfuerzos de inversión para el desarrollo de la economía, etcétera. Configura todo ello un momento de disponibilidad general, pero ello condicionado por dos aspectos o núcleos de atención en el análisis, que no pueden ser borrados:

- Primero, que la propia dispersión o aniquilación o esfuminación del bloque previo de poder, que es algo distinto de un mero desplazamiento o ampliación, no implica por fuerza la sustitución del tipo de Estado existente, o sea que la continuidad de un mismo proceso capitalista puede contener varias revoluciones burguesas y no una sola, o sea que una nueva clase burguesa destruye y sustituye a la otra, con lo que se cumple el requisito del carácter revolucionario, que está además confirmado por su tipo de alianzas, lo cual es posible, por otra parte, debido a la modalidad regresiva del bloque anterior, que impide la unificación de la burguesía en el seno del Estado.

- En segundo lugar, que el tipo de pugnacidad que se instala en el seno de la revolución burguesa triunfante - no solamente entre las clases del pacto revolucionario, sino aun en su extensión hacia las contradicciones dentro del núcleo, que no tarda en hacerse monopólico, del nuevo aparato estatal, germen de la burocracia-, resultan decisivas para señalar la manera de todo el desarrollo ulterior del proceso. 
En todo caso, con lo que esto tiene de necesariamente provisional, es por estas razones que estudiar las actuales tendencias clasistas que se dan en Bolivia es algo que debe hacerse a partir de ese momento. La desigualdad básica del desarrollo ideológico es algo que conviene tener en cuenta. Aunque el horizonte de visibilidad está dado por el año 1952, sin embargo lo que entonces no aparecía sino como un matiz, puede verse ya en forma, es decir, con cuerpo bien delineado, en 1974, así como lo que pudiera parecer una adquisición invulnerable de ese momento, la libertad de las clases en el seno del Estado democrático, por ejemplo, puede extinguirse, y hasta la propia clase, a la vez que acumula sus formas de conciencia, puede recordar un momento de su atraso, etcétera. Se requiere, pues, una estimación sintética o estructural del proceso, que no puede servir a secas a la línea de la sucesión cronológica y que en cambio ha de optar por el aislamiento de coyunturas para la obtención de categorías de desarrollo.

\section{LA CARGA IDEOLÓGICA (MNR)}

En los acontecimientos de 1952 sin duda es ya la clase obrera el actor principal. Pero es el actor principal a través del Movimiento Nacionalista Revolucionario (MNR) y en medio del MNR. Esto es lo que va a explicar su inicial facilidad en el pacto con las otras clases del movimiento democrático (como el campesinado) y su posterior obstáculo o divorcio de ellas. Es algo que tiene también un origen histórico. El MNR demuestra ser el más eficaz de los partidos que postulaban, en el comienzo de los cuarenta, la revolución democrática. Su eficacia se demostró precisamente en su doble capacidad de pactar a la vez con los sectores nacionalistas del ejército y con la clase obrera. La incorporación de la clase obrera al MNR se produjo como consecuencia de la denuncia que hizo el MNR, a través de sus parlamentarios y de su prensa, de la masacre de Catavi, en 1941. Hasta entonces los movimientos reivindicacionistas de las minas siempre habían terminado en el aislamiento y la represión focalizada, sin una verdadera repercusión en la política nacional como tal. En los hechos, sin embargo, 
la masacre de Catavi de 1941, a pesar de los esfuerzos norteamericanos por sostener a Peñaranda, decretó la caída de ese régimen, y eso demuestra que el acontecimiento minero había cobrado ya una envergadura nacional. El gobierno de Villarroel fue el resultado de ese pacto, y fue durante él (1944) que se constituiría la Federación Sindical de Trabajadores Mineros de Bolivia (FSTMB), que es hasta hoy el principal organismo sindical del país.

Después del derrocamiento de Villarroel, es algo ya muy evidente que el proletariado es el corazón del movimiento democrático. Toda la resistencia al régimen oligárquico, que dura de 1946 a 1952, gira en torno a la clase obrera. Desde el ciclo de huelgas de 1947 hasta la actuación armada de los mineros en Catavi y Potosí, en la guerra civil de 1949, el intento de insurrección en Villa Victoria, en La Paz, en 1950, y la propia insurrección de 1952, todo girará en torno a la clase obrera. Sin embargo, y a pesar de que los mineros aprobaron documentos tan independientes como la Tesis de Pulacayo, es notorio que consideraban al MNR como su partido, que lo que hacían lo efectuaban a través de él y que, en suma, aún no tenían intereses diferenciados con relación a la revolución democrática como conjunto. Por eso es importante ver cuál fue el contenido del MNR o, mejor dicho, su carga ideológica:

1. Es un partido formado, en lo básico, en torno a la crítica contra la oligarquía de empresarios mineros y terratenientes, crítica hecha desde los sectores de la pequeña burguesía urbana, en principio. Como es un país en el que el bloque oligárquico, la rosca, gobierna directamente por medio de sus funcionarios y no mediante los funcionarios del Estado, la crítica a la oligarquía se convierte de inmediato en crítica contra el Estado, contra el sistema estatal en su conjunto. Es decir, la crítica empírica contra la clase dominante se vuelca a la crítica genérica contra el Estado. La pequeña burguesía, o burguesía potencial, pugnaba en ese momento por la ampliación burguesa, por la expansión de la clase dominante, pero se daba cuenta muy temprano de que tal cosa no era posible sin la destrucción de la clase dominante. No se puede hacer crítica de clase a la clase dominante sin el reconocimiento 
derivado de las clases dominadas y, por consiguiente, la construcción de la alianza con los demás sectores oprimidos, que le sirven de catapulta, coincide con la transformación del proletariado en clase política en la década de los cuarenta y del campesinado en la de los cincuenta. La crítica a la oligarquía convocaba de facto a una democratización del sistema político.

2. La destrucción del aparato ideológico del Estado oligárquico. Esto arranca del correlato nacionalismo-indigenismo. El pacto entre el MNR, cuyo programa tenía un violento sentido xenófobo y que hablaba de fundarse en la raza mestiza, con la liga militar Radepa (Razón de Patria), tenía este contenido. Se trataba de un llamamiento de corte plebeísta, adecuado al tipo de movilización que se proponía el movimiento.

En el gobierno de Villarroel se actualizó, como decisión de gobierno, la polémica Tamayo-Arguedas, que databa de 1910, y que a su turno provenía de la más antigua entre Rafael Bustillo y Juan Bautista Alberdi. Se editó el libro de Tamayo La creación de la pedagogía nacional, que se convirtió en una suerte de evangelio de los militares nacionalistas. Es una tesis racial-indigenista, es decir, la raza vista como motivación por el sector oprimido más extenso del país, pero la fuerza formidable que tenía el planteamiento en lo intelectual, en un país con un contenido indígena tan vigoroso como Bolivia, no podía sino alcanzar un gran reclutamiento.

Esto pertenece, como es natural, a lo que se puede llamar el aparato mítico de la movilización democrática en su momento más atrasado, pero tratar de encontrar en la Creación de la pedagogía nacional una explicación científica del proceso democrático sería tan absurdo como intentar explicar la unidad alemana a partir de los Discursos a la nación alemana de Fichte, aunque posiblemente ni 1952 ni la unidad alemana habrían sido posibles sin esta suerte de convocatorias irracionalistas y eficaces. Por lo demás, cumplen una función parecida a las discusiones sobre la religión que Engels describe como una traducción esotérica de más auténticas exigencias revolucionarias en el campo político, en la primera época de la izquierda alemana. Los bolivianos de ese tiempo discutían como raza lo que en realidad pensaban como clase, y este 
tipo de incentivos patetizantes era imprescindible para llegar al tiempo en que ya no fueran necesarios. Después de 1952, la consigna racial ya había quedado atrás. A ellos les parecía que el dato más íntimo de reconocimiento de lo nacional era el ser material, cuyo modo humano era la raza, pues el fin que se proponían era lo nacional, la nación.

Otro aspecto igualmente relevante de la destrucción del aparato ideológico del Estado oligárquico fue la revisión histórica. Aunque no vale la pena entrar en detalles, es evidente que el carácter de guerra agraria que tuvo el extenso fenómeno de las republiquetas, las contradicciones entre los azogueros y la Corona, o entre los dueños de obrajes y los comerciantes de Buenos Aires, o la lucha de clases en torno a la movilización popular de Manuel Isidoro Belzu y la contrarrevolución de Melgarejo, su recreación de la clase latifundista con base en el reparto de las tierras de comunidades, el gran movimiento agrario de los Willka, que engendró y que remató en el movimiento campesino de Zárate, en la Guerra Federal de 1899, en fin, el papel de las masas en general en la historia de Bolivia, era sistemáticamente encubierto por la historiografía oficial. Montenegro hizo esa revisión, que fue completada para el siglo XX por Augusto Céspedes, ambos ideólogos básicos del MNR.

3. En la contigüidad de una temática con la otra, es obvio que el indigenismo concebido como lucha entre las clases nacionales contra la casta extranjera (el propio descendiente del español en cuanto clase dominante, era considerado por el MNR como un extranjero), no podía sino traducirse en un programa agrario. La combinación entre el razonamiento indigenista y la movilización campesina, que es anterior al 52, hacía inevitable la revolución agraria y la consiguiente destrucción de los terratenientes señoriales clásicos.

Pero la lucha de clases, cruz del éxito del movimiento, no lo es en el sentido de la posición marxista, "que — lo decía Montenegro- se siente clase en vez de sentirse nación", sino que, entendiendo la historia de Bolivia como la contradicción antagónica entre la nación —es decir, entre las clases nacionales, que la plebe 
considerada en su lecho de conjunto- - y la oligarquía extranjerizante, o extranjera ella misma, la oligarquía o la antinación, o antipatria. La propia clase obrera era tomada por Montenegro, por ejemplo, como la dirigente de las clases nacionales, pero sin destino al margen de su fusión con las demás clases nacionales. Aquí está el concepto de que "la oligarquía impide la unidad del pueblo"; pero después de la oligarquía, el pueblo es uno, supuesto populista que forma la base del policlasismo del MNR, lo cual, si no hubiera llegado a producirse la falla por el polo proletario, debió haber sido el asiento o soporte de la futura burocracia estatal.

4. La fuente proletaria. La imbricación MNR-clase obrera es, en el principio, un dato fáctico. Simplemente nacen juntos a la política, y el MNR es, por ejemplo, el creador de la FSTMB, que es hasta hoy el centro organizativo principal del proletariado. Como el MNR era, en la práctica, la federación de todos los grupos antioligárquicos, es evidente que los obreros, en aquel momento del desarrollo de su clase, se movían con soltura dentro del MNR y no encontraban nada en su vida diaria que los empujara a diferenciarse del MNR.

Sin embargo, la historia de los obreros en el MNR será la historia de su creciente diferenciación con el propio movimiento democrático en general; la lucha por conservar su identidad dentro del lugar de su alianza con las otras clases será a la vez lo que configure la construcción de su independencia de clase. Esto se funda, en primer término, en ciertos logros programáticos internos, como la Tesis de Pulacayo, que es aprobada en 1947, bajo la indudable influencia trotskysta. Pero un programa avanzado no garantiza todavía una avanzada práctica de clase. Se funda, en segundo lugar, y de una manera más importante, en el hecho de que el proletariado resulta un caudillo automático, una clase más eficaz, penetrante y organizada que cualquiera otra inclusión dentro del pacto democrático; resulta, en consecuencia, de su propio poder de hecho, que sale a la luz en los grandes acontecimientos de 1952.

5. El antiimperialismo, que pasa de ser una retórica heredada de la reforma universitaria a un análisis de situaciones concretas 
a partir de la revisión de la cuestión del Chaco, en la que, sin du$\mathrm{da}$, juegan un papel fundamental la década infame argentina y el imperialismo inglés. Montenegro, por ejemplo, que fue quizá el hombre más influyente en la formación ideológica del MNR, tuvo un papel muy notorio en la nacionalización de la Standard Oil en 1937. La lucha posterior contra los llamados "precios de democracia" para los minerales bolivianos y en el no reconocimiento de Villarroel por los Estados Unidos, aparte de la doctrina Rodríguez Larreta y el Comité Guani, organizados para acosar a los regímenes de Perón y Villarroel, dejaron una tradición antinorteamericana en el MNR; pero es una tradición que sería rápidamente relegada a los pujos de la violenta lucha de clases desatada en 1952. El imperialismo, entonces, con la actitud pragmática que adoptó Eisenhower, se convirtió en una amenaza mediata en su cotejo con el inmediato acoso del movimiento obrero. Éstas son no sólo las influencias en general, sino también el orden de influencias en la creación de este movimiento.

\section{EL ESTADO DEL 52}

El Estado burgués se constituye, entonces, antes que la burguesía; pero hay que distinguir entre la necesaria dependencia relativa de la fase de la clase obrera respecto de la fase del Estado burgués, y la falacia que supone que el desarrollo de proletariado corresponde al desarrollo de la burguesía. Con este recaudo, distinguimos cuatro fases dentro del ciclo del MNR, o si se quiere, del Estado del 52, que estamos viviendo todavía:

1. Fase de la hegemonía de las masas. Aquí el proletariado es la clase dirigente del proceso democrático-burgués. El aparato represivo es el pueblo en armas; el ejército ha sido disuelto en la batalla del 9 de abril. La oligarquía es reprimida en cuanto clase, y la represión en gran medida está en manos de las propias masas. El proletariado, aunque no ha asumido todavía el carácter de clase para sí, impone o ejecuta por sí mismo el carácter radical de las medidas adoptadas en torno a la nacionalización de los 
capitales extranjeros en la minería, y la revolución agraria. Es la clase obrera la que arma a las demás clases del pacto democrático y la que las organiza. La organización de las masas es la principal adquisición democrática de ese período.

2. Fase semibonapartista del poder. Éste es el momento que mejor se aproxima al modelo estatal concebido en el proyecto del MNR. Aunque fue pensado como un estatuto de largo plazo, a la manera del sistema mexicano, no obstante, la autonomía relativa del Estado emerge aquí como un cruce ocasional o forma de tránsito; una correlación de modos de producción en flujo y la propia articulación atrasada de un modo de producción con el otro ofrecen una base impropia para la práctica real de la ilusión teórica de la autonomía del Estado. No obstante, esta independencia relativa, inmediatamente circunstanciada, se expresa en la aparición del subfenómeno de la mediación.

La burocracia lechinista actúa como mediación con relación a una clase obrera en situación de reflujo; los caciques se han convertido en intermediarios con el campesinado, que domina el territorio, y el propio Ovando, que es el agente de la reorganización del ejército, y por consiguiente el jefe titular de la burocracia estatal militar, es un mediador con relación al ejército. Se negocia ya con el imperialismo, aunque todavía desde una posición de cierta fuerza y autodecisión que se basan en las masas.

3. Fase militar-campesina. Aquí es ya importante el desdoblamiento en el seno de la burocracia. Como la autonomía relativa es un paso cualitativo o ascenso de la unidad de la burguesía, allí donde no existe la unificación estatal de la burguesía, que es impensable aquí, porque la burguesía no existe ante sí, no está sino en el arranque de su acumulación misma, tampoco hay unidad de la burocracia estatal. En todo caso, la burocracia que surge como soporte del nuevo Estado en la suma de sus órganos, se alía con el sector más atrasado, satisfecho y estático de las masas, bajo la dominación directa del imperialismo. La presencia semicolonial de los norteamericanos en el aparato represivo del nuevo Estado es un dato impactante de la modernización de ese aspecto represivo. Los mecanismos de mediación sobreviven todavía, pero el 
concepto mismo de mediación está siendo rápidamente sustituido por el de control estatal. La ruptura política entre la burocracia civil y el proletariado minero, que queda momentáneamente aislado, es montada por la inteligencia imperialista, y facilita la emergencia de estas fases conservadoras del nuevo aparato.

4. Fase militar-burguesa. La burguesía ya se ha reconstituido como clase, es decir, se ha constituido como clase política en su nueva extensión, y la derecha militar se ha enlazado con ella. La mediatización en el campo es en ciertos sectores lo suficientemente estable como para que se abandone el pacto militar-campesino o los sectores campesinos, que se rebelan como resultado del nacimiento de nuevos apetitos democráticos, sigan la misma suerte que la clase obrera, o sea que se ejerza una dictadura frontal sobre la clase obrera y sobre todos los sectores que secunden su descontento. Todos los sectores propiamente estatalistas han sido desplazados.

\section{CONDICIONES DEL CAMBIO DE FASE}

Desde luego, no es el objeto taxonómico lo que aquí interesa, sino la adopción de perímetros de análisis. Cuando los fenómenos sociales ocurren sobre masas en movimiento, no sólo los codos de ruptura, sino los propios cambios de acentuación, no pueden ocurrir sino por medio de golpes de mano o imposiciones bruscas desde el lugar social donde se asienta el poder real. En efecto, no se puede concebir, por ejemplo, la sustitución de la fase 1 por la fase 2 sin que se produzca un codo de ruptura o desgarramiento, que está dado por el desplazamiento del aparato represivo del Estado del pueblo en armas al ejército reorganizado. Se da un cambio de carácter de clase en el aparato del Estado burgués; no es ya el proletariado el que encabeza la revolución burguesa, sino la burocracia que, defensivamente, opera como conjunto. Es un golpe de Estado dado por la burocracia contra el proletariado.

El desbaratamiento de las fases siguientes, como contraparte, implica solamente la subrogación de hegemonías de las fracciones dentro de la burocracia, como administradora del poder 
estatal burgués o de la burguesía misma, que ensaya su poder directo unificado contra la burocracia y el proletariado. Pero es una linealidad expositiva. Con Torres, por ejemplo, el proletariado ensaya ya su retorno al estatuto del 52 , en condiciones que han sufrido sus naturales mutaciones y, en cambio, la burocracia miliar intenta restablecer el momento semibonapartista, con la consecuencia de ser vencidos ambos. Pero no es un solo proyecto el que se derrumba, sino dos: sólo la derrota los une; cada uno es vencido en su propio propósito.

\section{LA TEORÍA DE LAS ETAPAS}

La propia discusión en torno a las primeras fases de la revolución burguesa, el examen provisional de sus resultados, tienen como efecto la creciente diferenciación entre las posiciones sociológicas burguesas y la interpretación proletaria.

Para la clase obrera, por ejemplo, una pregunta capital era la que se refería a por qué hay hegemonía proletaria en 1952, una hegemonía automática, no preconcebida en concepto por nadie, y por qué se produce la pérdida de hegemonía.

La prueba de que la clase siente como insuficiente una explicación subjetiva de dicha pérdida está en que sus dirigentes, los que presuntamente habrían entregado el movimiento de masas, no son desplazados. Es una clase menos cautelosa. La división del movimiento obrero habría sido, en esa coyuntura, un hecho inevitable. Aquí, por cierto, hay una temprana conciencia de que la clase debe moverse siempre como toda la clase, o sea que, como dice el Manifiesto comunista, los sectores avanzados del proletariado "no tienen intereses que los separen del conjunto del proletariado", que el proletariado, en suma, debe vivir como conjunto su propio atraso y su propia evolución. La condición natural es la existencia de la democracia proletaria, es decir, la democracia de la clase para sí misma, la lucha ideológica en el interior de la clase.

En segundo término, como derivación, viene la crítica de la teoría de las tapas y su consecuencia, que es la asunción de la tesis de mayoría general. 
Se sabe de dónde viene, en Bolivia, la teoría de las etapas. La descripción más clara de esta posición sigue siendo hasta hoy la esbozada por el teórico del MNR Walter Guevara en su documento Manifiesto a los electores de Ayopaya, aunque no es la única, ciertamente. Guevara postula allí específicamente que la revolución burguesa debía cumplirse a plenitud en el país para que fuera posible después plantearse la revolución socialista. Guevara, en lo que posteriormente sería una práctica política muy generalizada en Bolivia, aplica la jerga y las propias categorías del marxismo a una postulación propiamente burguesa; es explicable, por otra parte, que el mismo Guevara, a partir de la posición de las etapas, en el momento del paso del proletariado de clase hegemónica a clase complementaria del poder, terminara por postular, con menos rigor aún que en el Manifiesto, que la dirección de la revolución correspondía a la clase media, situándose así a la derecha de la propia burocracia estatal.

La implicación de las tesis de Guevara abarcaba, sin embargo, a todos los sectores no proletarios del régimen. Era un supuesto de ellas advertir que el propio desarrollo de las fuerzas productivas, tácito en el impacto revolucionario, convocaba a un desarrollo conjunto, paralelo e intercorrespondiente de la burguesía y el proletariado, y que debía hablarse por tanto de revolución nacional.

La crítica de la teoría de las etapas suscita varias conclusiones sumamente útiles para el conjunto de ideas que designamos como sociológica de la clase obrera. En primer término, que el desconocimiento de las etapas, que es un impulso característico de masas en las que el carácter espontáneo prima todavía sobre su desarrollo consciente, no puede conducir sino a que las etapas se expresen contra la clase obrera, en mengua de su capacidad real de poder. En segundo lugar, que las etapas, sea que se considere a la revolución burguesa misma como una etapa, sea que uno considere las etapas en el seno de la revolución burguesa, pueden y deben ser cumplidas bajo la hegemonía y el poder de una clase no burguesa y, en el caso, del proletariado. En tercer lugar, que es demagógico hablar de clase media en el mismo sentido que se habla de burgue- 
sía o de proletariado, y que dicha mención se refiere al punto en el que emerge la burocracia estatal semibonapartista o, más bien, al lugar social en que el desarrollo de la burguesía no es el desarrollo del proletariado, sino en su aspecto excedente, el cuantitativo, y aun eso dentro de determinadas formas de desarrollo económico y que, por consiguiente, es totalmente concebible la ejecución de las tareas burguesas al margen de la burguesía.

Pero, en los hechos, cualquiera fuera el orden de sus protestas ideológicas, el proletariado se vio obligado por la combinación de su débil desarrollo cualitativo (que hacía una paradoja con la densidad de su poder material) y la urgencia derivada del bueco estatal que acompañaba a la crisis nacional del 52.

¿Qué quería decir empero aquello de que se vio obligado? En 1952, el proletariado no tenía intereses que lo diferenciaran del campesinado; pero, al realizar la consigna burguesa de la tierra, al dirigir el proceso de la revolución agraria, al mismo tiempo que cedía la forma del aparato estatal a la pequeña burguesía, el proletariado estaba habilitando al movimiento campesino para pactar directamente con el Estado, desde el que había recibido la tierra, al margen del proletariado. Por lo tanto, mientras en 1952 tenía una cómoda hegemonía, aun a pesar de su inconclusión interna de clase, porque representaba a la mayoría general, en 1954, cuando la crisis ya se expresaba como falta concreta de productos, tenía ya que atenerse a su mera fuerza numérica, sus intereses se habían diferenciado de los del campesinado: se veía relegado a un rol complementario y era, en suma, una clase aislada, que había avanzado, pero al precio de romper la alianza que era la clave de su poder. Objetivamente, esta misma clase que repudiaba la teoría de las etapas había venido a practicarla. Claro está que, en un análisis superficial, habría quien dijera que esto ocurría porque la izquierda no había leído sobre el impuesto en especie. Pero la subsunción de la teoría no se realiza a través del conocimiento teórico, sino por medio de la discusión de la clase en su momento concreto.

El segundo sector de desconcierto de la izquierda se sitúa en la órbita de las ideas económicas. En lo que es una curiosa paradoja 
con relación a las ideas argentinas de la misma época, que establecían que el mal de su país radicaba en la extensión, en Bolivia se desarrolló, prácticamente desde el principio del siglo XIX, el concepto de la inferioridad geográfica del país.

El propio mariscal Santa Cruz, con su frustrada Confederación Perú-Boliviana, estaba sin duda ya practicando estas concepciones especialistas que, por otra parte, se fundaban en un hecho harto real, cual era el desplazamiento de los centros interiores a los puertos por la llegada del comercio inglés.

Pero fue el Plan Bohan el que entrevió, a principios de la década de los cuarenta, las posibilidades de un avanzado desarrollo capitalista en torno al área de Santa Cruz de la Sierra, en la parte occidental de los llanos orientales. La gente del MNR, por lo demás, tuvo ocasión abundante de ver en la Guerra del Chaco las dimensiones de la no integración territorial del país. En los hechos, no sólo la integración del Oriente, sino el propio cambio de eje económico territorial, en una franca fuga de la centralización en el altiplano minero, la tierra del "metal del diablo", se convirtieron en verdaderos fetiches de la política económica que puede inclinarse a voluntad sobre la base de la tabula rasa política del 52. De esta manera, Paz Estenssoro sobre todo, Walter Guevara y Alfonso Gumucio condujeron la ideología económica del MNR hacia una concepción geográfica, territorialista y agrarista del desarrollo. Todo ello, por lo demás, de un modo sugestivo en extremo en su coincidencia con los criterios circulantes en el momento alemán de la construcción de la unidad. Habría que recordar, por ejemplo, las menciones de Marx referentes a la inferioridad geográfica de Alemania y el papel de los ferrocarriles. Pero era algo que se hizo rápidamente coincidente con los intereses norteamericanos, que se situó de hecho dentro de la división del trabajo que podía admitir el imperialismo en ese momento y era, por tanto, una política típicamente burguesa en sus planes de integración, pero abandonando toda política de industrialización, que era posible sobre todo en torno a la minería nacionalizada y el petróleo, que resultaron prácticamente abandonados a su propia suerte. Como eso coincidió con la instancia del reflujo de la clase 
obrera, la izquierda no podía contraponer a esos planes sino una política defensiva, y era evidente que, tanto en el momento de su auge como en el de su influencia complementaria, era una clase obrera que carecía de ideas económicas con relación al mismo poder en el que, sin embargo, influía políticamente de un modo determinante.

\section{LA TESIS DE PULACAYO}

Consideremos, sin embargo, no el lado de la perplejidad del proletariado, sino de su lucidez, y en este orden de cosas sin duda la llamada Tesis de Pulacayo (tesis central de la FSTMB) es sin lugar a dudas la prueba más rotunda del carácter avanzado que adquirió esta clase desde su más temprana aparición en la política del país.

Para mencionar sólo algunos de sus aspectos, los más generales, una correcta tipificación de la formación económico-social del país:

Bolivia es un país capitalista atrasado. Dentro de la amalgama de los más diversos estadios de evolución económica, predomina cualitativamente la explotación capitalista, y las otras formaciones económico-sociales constituyen herencia de nuestro pasado histórico. De esta evidencia arranca el predominio del proletariado en la política nacional. ${ }^{2}$

Una definición sin duda sorprendente, si se la ubica en la fecha de su aprobación, noviembre de 1946, bastante antes de que la cuestión de las formaciones económico-sociales y de los modos de producción fuera discutida en el continente.

Por otra parte, la tesis sostiene que

[...] la particularidad boliviana consiste en que no se ha presentado en el escenario político una burguesía capaz de liquidar el latifundio y las otras formas económicas precapitalistas; de realizar la unifi-

2 Tesis de Pulacayo, 8 de noviembre de 1946. 
cación nacional y la liberación del yugo imperialista. Tales tareas burguesas no cumplidas son los objetos democrático-burgueses que inaplazablemente deben realizarse. Los problemas centrales de los países semicoloniales son la revolución agraria, es decir, la liquidación de la herencia feudal y la independencia nacional [...] El proletariado de los países atrasados está obligado a combinar la lucha por las tareas demo-burguesas con la lucha por las reivindicaciones socialistas. ${ }^{3}$

El desconocimiento de toda posibilidad de dirección pequeño-burguesa:

La clase media o la pequeña burguesía es la más numerosa y, sin embargo, su peso en la economía nacional es insignificante. Los pequeños comerciantes y propietarios, los técnicos, burócratas, los artesanos y los campesinos no han podido hasta ahora desarrollar una política de clase independiente, y menos lo podrán en el futuro. El campo sigue a la ciudad y en ésta el caudillo es el proletariado. ${ }^{4}$

Sobre quién debe encabezar la propia fase democrático-burguesa:

Señalamos que la revolución demo-burguesa, si no se la quiere estrangular, debe convertirse sólo en una fase de la revolución proletaria [...] Mienten aquellos que nos señalan como propugnadores de una inmediata revolución socialista en Bolivia; bien sabemos que para ello no existen condiciones objetivas. Dejemos claramente establecido que la revolución será democrático-burguesa por sus objetivos y sólo un episodio de la revolución proletaria por la clase social que la acaudillará. La revolución proletaria de Bolivia no quiere decir a las otras capas explotadas de la nación, sino alianza

\footnotetext{
3 Ibid.

4 Ibid.
} 
revolucionaria del proletariado con los campesinos, artesanos y otros sectores de la pequeña burguesía ciudadana. ${ }^{5}$

En cuanto a su proyecto estatal:

La dictadura del proletariado es la proyección estatal de dicha alianza. La consigna de la revolución y dictadura proletarias pone en claro el hecho de que será la clase trabajadora el núcleo director de dicha transformación y de dicho Estado. Lo contrario, sostener que la revolución democrático-burguesa, por ser tal, será realizada por sectores "progresistas" de la burguesía y que el futuro Estado encarnará en un gobierno de unidad y concordia nacionales, pone de manifiesto la intención firme de estrangular el movimiento revolucionario. ${ }^{6}$

A pesar de lo extraordinario que resulta que el proletariado como conjunto adoptara una tesis tan avanzada en un momento en que, después de todo, no había dicho todavía su plena palabra, la historia fue más lejos que la tesis, o cumplió sus previsiones de un modo más retorcido y, por otra parte, resultó muy evidente que la clase no tenía las condiciones para llegar allá donde llegaba sin embargo su tesis.

Por ejemplo, en el problema que Marx llamaba de la "iluminación" desde el sector de punta. Primero habría que resolver si no es posible la existencia del foco o enclave capitalista como enclave mismo, es decir, como un polo en el que, si se quiere, hay un modo de producción capitalista, pero no articulado con los demás sectores de la formación, cuyo único dato de unidad es el dato político, lo que algunos llaman el Estado aparente.

Aquí no sólo falta la propalación del modo principal, sino que puede faltar la articulación misma. No era el caso, por cierto. El mero hecho de que se hablara de la rosca como la combinación entre los latifundistas y la empresa minera mostraba ya que la

\footnotetext{
5 Ibid.

6 Ibid.
} 
iluminación existía. Pero aquella burguesía propiamente oligárquica, muy preocupada con su restricción y no con su expansión, era en cambio el freno principal con que se encontraba no sólo el proletariado (que era sin duda su enemigo), sino las propias clases preburguesas, los sectores que ya se sentían en disposición de convertirse en burguesía. Es cierto que lo que había de iluminación era lo que permitió al proletariado avanzar sobre las capas campesinas y aliarlas a su tarea (no por azar el centro de la revolución agraria fue Cochabamba, la zona más integrada a la economía minera); pero lo que no había de propalación del modo de producción de punta impidió la expansión numérica del proletariado y, en la fase de su aislamiento, que era previsible aunque no está en la tesis, el hecho numérico se volvía decisivo. El cerco de la clase obrera se convirtió en una muralla china.

Esta preburguesía, o si se quiere, los agentes políticos de la burguesía en construcción, lograron a su turno canalizar la revolución agraria (que, en efecto, implantó el proletariado de acuerdo con todo el mandato de la tesis) y plantearon la unidad nacional de una manera propiamente burguesa; la claudicación estatal del proletariado no le permitía realizar las tareas burguesas que la burguesía no había sabido realizar. Estas tareas volvieron a su titular, aunque, obviamente, se limitaron a lo que se le permitía hacer a una burguesía dependiente.

Para mayor abundancia, el campo no siguió a la ciudad sino hasta realizar sus propias consignas; la alianza con el campesinado y la pequeña burguesía urbana fue mucho más inconstante de lo previsto y, en fin, el propio proletariado acabó practicando no su tesis, sino la de sus rivales (la teoría de las etapas, por ejemplo), o sea que la clase considerada como conjunto que no había tenido tiempo de asumir su propio programa. El programa, a su turno, habría necesitado de un contorno teórico, que lo desarrollara y, además, cuando se es tan poco numeroso y las alianzas son tan decisivas, habría sido necesario que incluso los sectores más avanzados de las otras clases de la alianza tomaran este programa como propio, es decir, que se diera una irradiación. Pero nada de esto alcanza para disminuir la suprema importancia histórica de este 
tipo de adquisiciones; se puede comentar la tesis o transformarla o explicar por qué no se cumplió a la hora de la crisis, pero las clases no retroceden del punto al que han llegado con sus programas, y la educación de la clase se hace en torno a eso.

\section{DETERMINACIÓN DERIVADA DE CLASE}

Hacia 1952, arrasado el sistema político oligárquico y su propia base económica, prácticamente disuelta la clase de los terratenientes del campo, la burguesía (la que existía como grupo marginal al Superestado minero, es decir, la burguesía tomada en su expresión concreta y no en su contenido histórico) estaba reducida a su expresión mínima y no disponía de perspectivas. Sin embargo, ése fue el momento en que se organizó el moderno Estado burgués boliviano, al cual llamamos por eso Estado del 52. Se puede decir que en ese momento, porque lo querían conscientemente o porque no tenían otro remedio, todas las clases perseguían fines burgueses, menos la burguesía, que seguía atada a la costumbre de una superestructura derrotada. Pues al no poder fundarse en la propia clase a la que quería servir, el Estado en este caso es anterior a la clase a la que serviría; el Estado abrogaría sin miramientos el germen burgués sobreviviente, crearía su nueva burguesía, le daría el tiempo, los medios y la imaginación para que se constituyera como clase.

Ésta es la cuestión de la determinación derivada de una clase en otra. Sin duda, no era la primera vez que una clase social daba lugar al poder de otra y, por último, en su consecuencia histórica diferida, a la constitución de una tercera. Esto es, por el contrario, algo clásico de las revoluciones burguesas de tipo democrático.

En el caso boliviano, es la clase obrera la que conquista un poder para el que no es capaz todavía, como clase misma, y lo entrega a su aliado más verosímil como clase burocrática, que es la pequeña burguesía, portadora ya de los ideales burgueses (aunque en contradicción concreta con la burguesía misma preexistente), que es débil y carece de un proyecto propio, que es 
incapaz siquiera de la tarea de interpretar el hecho. La burguesía nueva se construye aplastando políticamente a la vieja burguesía.

\section{CAOS SOCIAL Y PEQUEÑA BURGUESÍA}

El núcleo de ubicación de la acumulación originaria de la burguesía, de la que tampoco puede decirse que se constituya como clase política sino alrededor de 20 años después, es el Estado.

Como los mismos supuestos ideológicos (que como hemos visto eran difusos) pueden dar lugar a diferentes desarrollos, es probable que la propia fase de la dictadura de las masas (1952) haya dado lugar a que maduraran en el seno de la MNR propensiones que ya estaban de un modo germinal en su interior.

En el supuesto de que la desgracia del país no era la existencia de una burguesía, sino la insuficiente existencia de una burguesía nacional y su correlato, la lucha por la integración nacional, la construcción del Estado nacional, los puntos de acumulación, se enquistaban en el capitalismo de Estado (creado en su parte fundamental por la racionalización de las grandes empresas mineras) y las zonas de recursos naturales de nueva apertura. En lo que era ya un plan consciente, la Comibol se convirtió en empresa generadora de empresas, en empresa de construcción de la burguesía comercial ampliada y, por otro lado, sus excedentes fueron desviados hacia el desarrollo capitalista de Santa Cruz de la Sierra.

Esta es la razón por la que la lucha obrera giraría - tanto en el tiempo de la Tesis de Colquiri como durante la Asamblea Popular- en torno a la cuestión de la minoría nacionalizada.

Mencionemos ahora el impacto del caos económico-social, o lo que se vive como caos, que es el vuelco del estilo cotidiano de vida social, en los grupos intermedios. No es el de Bolivia, por cierto, el único caso en que la revolución democrática se acompaña de una gran crisis agrícola, un desorden general en la economía, aparte del descenso de la producción minera y el desatamiento de la inflación en gran escala. Esto no afectaba de una manera decisiva a los campesinos que, aun sin aportar excedente agrícola al mercado, en el peor de los casos mantenían sus 
condiciones de vida en un estatus que se hacía ventajoso porque iba acompañado de la expulsión de los patrones, de la libertad política y la participación. Ya entonces, en efecto, los campesinos dieron la base social para la supervivencia del esquema político, y por el otro lado, aunque esto Eder jamás habría podido entenderlo, incluso la llamada estabilización monetaria, que fue quizá el más drástico plan antiinflacionario implantado en la América Latina, habría podido sobrevivir si los campesinos no hubieran comenzado entonces a practicar su concurrencia al mercado.

La situación era bastante diferente en lo que respecta a la pequeña burguesía urbana. Despojada de sus privilegios políticos, con el voto universal, clase cuya pretensión era conservar el orden social abstracto, a diferencia de los obreros y los campesinos sin tierra, que aspiraban a sustituirlo, grupo de ahorristas, empleados, artesanos, comerciantes sin reservas económicas, etcétera, no podían sino vivir como un momento demoníaco, aquel de la ruptura del orden político, que iba además acompañado de un proceso inflacionario violento. El proletariado, incapaz de retener la concentración del poder en torno a sí mismo, luchando en los tiempos siguientes por retener la fuerza inicial, desorganizando aún más el sistema, no podía ofrecer a la pequeña burguesía su propio orden en la política ni en la economía.

$\mathrm{Al}$ no caber ni existir una respuesta diferente a esta crisis, se produce el reingreso del imperialismo norteamericano por la vía de la ayuda. Tal como se ha dicho antes, el imperialismo a su turno confirma las características del plan de desarrollo agrarista y territorial del MNR y lo fortifica canalizando su ayuda en el mismo sentido, es decir, acelerándolo. El precio que se paga por esta ayuda es la interrupción específica de todo hipotético plan de industrialización que, en ese momento, sólo podía concebirse en torno a la producción minera. En los hechos, Estados Unidos impone que el proyecto de constitución de la burguesía se dirija hacia la producción primaria, y suprime toda posibilidad de creación de industrias pesadas y de integración de la minería, que habrían sido su único remate racional. Pero esto se basa ya en la quietud o satisfacción del campesinado y en el élan del orden en 
la pequeña burguesía urbana, que está dispuesta a pagar cualquier precio por ello y que, no hay que olvidarlo, es la mayoría de las ciudades. Esto se puede decir también de otra forma: una mayoría conservadora había sustituido a la mayoría revolucionaria del pueblo y exacerbado los aspectos moderados que preexistían a ambas, mayoría conservadora y mayoría revolucionaria, en el seno de la clase burocrática.

\section{LA TESIS DE COLQUIRI}

Tales son, entre otras, las razones por las que un programa más avanzado que la capacidad de poder real de la clase no puede aplicarse aún en el momento de control material de la situación que logra el proletariado en 1952. Sin embargo, aunque los obreros no consolidaron la continuidad de su ofensiva, demostrarían en los años siguientes su extraordinaria consistencia defensiva. Fue por medio del fracaso de los intentos de organizar mecanismos de mediación correspondientes a la fase semibonapartista que se derrumbaría el proyecto histórico del Estado burgués de 1952.

Ya durante el gobierno de Siles Suazo (1956-1960), el régimen se empeñó en la construcción de un sindicalismo dependiente del Estado, a la manera de lo que había ocurrido con los sindicatos campesinos. Aunque no vale la pena entrar en la anécdota de estos acontecimientos, por lo menos el incidente producido hacia 1958 entre los sindicatos de Catavi y Huanuni es algo que resulta ilustrativo. Los mineros, a partir del Plan de Estabilización, que constituye el verdadero reingreso del imperialismo de los manejos de los asuntos bolivianos, estaban ya en oposición al régimen del MNR. El gobierno logró éxito por lo menos en ciertos puntos, como Huanuni y las minas del sur. Se produjo entonces un enfrentamiento armado sindical que concluyó en la toma de Huanuni por los mineros de Catavi-Siglo XX, hechos que incluían la ejecución del dirigente principal de la línea gobiernista, Celestino Gutiérrez. Era, todavía, la imposición del aparato armado que conservaban los mineros del año 1952. 
Todavía el proletariado minero tenía influencia en el MNR como para imponer la vicepresidencia de Lechín, cuando Paz Estenssoro fue elegido presidente por segunda vez, en 1960. Pero Paz Estenssoro completaría la línea iniciada por Siles, con el llamado Plan Triangular, que reorganizó la minería nacionalizada excluyendo el Control Obrero y otras formas de participación proletaria en el manejo de las minas. La Tesis de Colquiri expresa este período de ruptura del proletariado con el Estado bonapartista, lo que, por otra parte, selló la imposibilidad misma de desarrollo de dicha forma estatal.

Veamos algunos de sus puntos:

- "El gobierno ha demostrado la manera persistente y que no ofrece la menor duda, que está vivamente interesado en eliminar toda injerencia obrera en el manejo de las empresas y de la cosa pública”. (Referencia a la supresión del Control Obrero con derecho a veto y otras medidas). ${ }^{7}$

- "Declara que los sindicatos no deben convertirse en agencia de partido político alguno, aunque éste se encuentre en el poder y se autodenomine revolucionario. La Federación no sustenta el apoliticismo, sino una política independencia de clase [...] De hoy en adelante, los mineros se colocarán a la cabeza de su clase para enseñarles a seguir su propio camino y a defender sus propios intereses, a marchar detrás de su propia bandera". ${ }^{8}$ Aquí se dan ya los elementos de la superioridad del sindicato sobre el partido como característica básica del movimiento revolucionario boliviano, a lo que nos referiremos después.

- "El sindicato es la forma elemental del frente único de clase, en cuyo seno coexisten las tendencias políticas y religiosas más diversas, con la única condición de que aquéllas se inspiren en principios revolucionarios". ${ }^{9}$

Tesis de Colquiri, prólogo y notas de Guillermo Lora, La Paz, s.e., 1964.

8 Ibid.

9 Ibid 
- "El gobierno pretende hacer trabajar a los mineros bajo la amenaza del terror y excluir total y radicalmente a la clase obrera de la dirección de la Comibol. Si prospera este criterio, se habrán acentuado las características burguesas de la estatización [...] Los obreros propugnamos una tesis opuesta: deben ser la capacidad creadora de la clase trabajadora (que se expresa sólo cuando está organizada colectivamente), su voluntad de vencer y la certeza de su rol dirigente las que se transformen en el cimiento real de una nueva administración de las mismas, que permita sacarlas de su actual caos y aumentar sensiblemente los índices de producción". ${ }^{10}$

- "La suerte de las minas es la suerte del país mismo y no puede plantearse al margen del destino del poder político". ${ }^{11}$ (En los dos párrafos anteriores se está gestando ya lo que se llamará proyecto de cogestión, que se planteará en la Asamblea Popular, en tiempo de Torres, como veremos también luego).

- "La revolución no tiene más garantía ni más defensa que las milicias mineras". ${ }^{12}$ (Esto es una reminiscencia del 52).

- "El gobierno antiobrero tiende a resolver los conflictos sociales mediante la despótica intervención de las Fuerzas Armadas [...] Los mineros sólo podemos tener una respuesta a esta situación concreta: armarnos y disciplinarnos, a nuestro turno, para rechazar con la violencia la amenaza de masacre [...]"13 (Ya se está definiendo el rol de árbitro de la situación que asumen las Fuerzas Armadas, entre el Estado bonapartista, cada vez con menos sustento de clase, y el proletariado, que se ha desvinculado de él. Ésta es la base de la fase militar-burguesa del Estado del 52).

Se puede situar entre los años 1956 y 1964 el período de desprendimiento de la clase obrera del MNR, es decir, del movimiento democrático burgués como conjunto. Pero puesto que la burgue-

$\begin{array}{ll}10 & \text { Ibid. } \\ 11 & \text { Ibid. } \\ 12 & \text { Ibid. } \\ 13 & \text { Ibid. }\end{array}$ 
sía misma no era capaz de concebir su proyecto estatal, y que la propia burocracia, la verdadera portadora de dicho proyecto, no habría podido sostenerlo sino en tanto estuviera sostenida a su turno por la clase obrera, fácil es advertir hasta qué punto, junto con el proyecto burgués burocrático, fracasó también la única perspectiva auténtica de que podía disponer la burguesía que se estaba conformando. Con todo, es notorio el carácter defensivo que ya tiene esta tesis, que sin duda es mucho más coyuntural que la de Pulacayo; aunque los obreros denuncian la defección del MNR, no dejan de situar la debacle del esquema del 52 en su verdadero punto de agotamiento: "El imperialismo — dice la Tesis de Coloquiri- ba impuesto sus planes al gobierno del MNR".

El resultado de esta premonición de la ruina del proyecto burocrático estatal, de la frustración de la clase obrera como clase hegemónica sin capacidad estatal y de su diferenciación con relación al movimiento burgués, sería primero el repliegue hacia el sindicalismo mismo y, cuando ya haya una instalación inicial de los partidos obreros en su seno, el lanzamiento de su propio proyecto estatal, que se configuró en la Asamblea Popular de 1971.

\section{MODERNIZACIÓN DEL APARATO ESTATAL}

Un proceso como éste no podía ocurrir sin una modernización considerable del sistema estatal. Ello sucede por varias vías:

- Ampliación del área territorial real de alcance estatal mediante la integración económica y política de grandes zonas que, en lo previo, no eran sino periféricas al acontecimiento estatal.

- Expansión del ámbito humano de validez del poder mediante la democratización política y económica, que se traduce en la incorporación del campesinado al funcionamiento estatal.

- Reconstitución y ampliación del aparato represivo del Estado, con la creación del nuevo ejército.

- Construcción de un importante sector capitalista de Estado. 
- Constitución y desarrollo de un núcleo burocrático estatal e instalación de sus correspondientes mecanismos de mediación.

\section{CONTRADICCIÓN BUROCRÁTICA Y BURGUESÍA}

En este momento tenemos ya un poder político de dirección burguesa. Pero de ningún modo hay que confundir a un Estado que se ha modernizado, con un Estado moderno. Incluso dentro del puro segmento estatal, como ha ocurrido además con un modo tanto más terminante en cuanto al itinerario de los modos de producción, la alteración del tipo de sucesión de las categorías estatales europeas es todo un carácter histórico. Si el trabajo de la unificación, tomado en su consideración más general, es algo que abarca toda una época, comprendiendo a la vez sus aspectos especiales, humanos y de modo de producción, no es por cierto la menor de sus obtenciones aquella que se refiere a la propia unificación de la clase dominante - la burguesía, en todas sus fracciones- en el hecho estatal. La propia burocracia debería ser un fruto cualitativo de la unificación de las fracciones de la burguesía. En el caso boliviano, por el contrario, la burocracia dará el curso objetivo que haga posible la unificación de la burguesía, pero cuando ésta se unifique, verá a la burocracia como su rival y se producirá una regresión en la manera estatal, aunque dentro de la nueva dimensión dada.

Como es clásico en este tipo de revoluciones, el nuevo poder desarma a las masas que le han dado el poder. La reorganización del ejército es la forma que adquiere ahora el desarme de las masas, la sustitución de un aparato represivo por otro. La fase semibonapartista, que cumple con el doble papel de suprimir la crisis económica que proviene como secuela supérstite de la crisis revolucionaria del 52 y de iniciar la acumulación de la nueva burguesía, se asienta en la alianza entre la burocracia civil (el MNR) y la burocracia militar. De hecho, se trata ya de una dictadura tanto sobre las masas, que han perdido la actividad del 52 o están ya mediadas, como sobre los sectores reaccionarios, que todavía se proponían una restauración del estatus anterior a 1952. 
Con todo, ello no podía suceder sin importantes conflictos tanto entre las clases que en conjunto estaban interesadas en la revolución burguesa como entre los gérmenes y las fracciones dentro de las propias clases que se movían en torno al nuevo poder, es decir, a la nueva dominación.

El frente policlasista, que ya estaba encabezado de un modo directo por la pequeña burguesía después del fracaso estatal del proletariado de 1952, se fue apoyando cada vez más en la alianza entre el Estado y el campesinado. El Estado era todavía pequeñoburgués y la diferenciación de clase en el seno del campesinado no se había declarado aún. Con Siles Suazo y el segundo Paz Estenssoro, por ejemplo, ya era esta alianza la que mandaba; pero el proletariado, aunque vencido en su propósito de clase, aunque resistiendo a la política de desarrollo burgués en ascenso, se mantenía todavía dentro del MNR. Siles y Paz Estenssoro todavía podían usar a la clase obrera como argumento a contrariis para negociar con el imperialismo. O sea que esta alianza hizo el minimum para sobrevivir como burocracia; la falta dejada por el desahucio obrero del sistema, que no produciría sino unos años después, es lo que restaría margen de movimiento y aun de permanencia al proyecto burocrático.

Es del todo distinto lo que pasa con el ejército, es decir, con la burocracia militar. Ella fue fruto indirecto de la revolución, y en cambio sí un resultado directo del momento en que la revolución se vio obligada a pactar con el imperialismo.

Por el contrario, la reorganización del ejército fue una de las condiciones del reconocimiento por el imperialismo. Puesto que su propia existencia y la totalidad de su equipamiento provinieron de los Estados Unidos, fue un ejército que se organizó en los términos de aquellos que existían bajo control neocolonial norteamericano, y así ocurriría aun en aspectos de tanta inferencia local como lo que se llama su doctrina militar.

Por eso Barrientos significa ya la liquidación del período semibonapartista, el desplazamiento de la pequeña burguesía, que había logrado concretarse como burocracia semibonapartista, y la alianza directa entre la burocracia militar y el campesinado, con 
exclusión sistemática de la clase obrera. Nótese que sigue siendo una burocracia la que gobierna - la militar-, es decir, un sector de la clase estatal. Pero cuando la burguesía hubo concluido su proyecto de constitución, con Bánzer, se trataba ya de la alianza entre la burguesía minero-comercial del altiplano y la burguesía capitalista rural del oriente la que gobernaría el país. En todo caso, por su origen, su ideología y su papel concreto, el ejército representaría en la política al estatuto semicolonial, en tanto que la clase obrera, en ausencia de una burguesía ya constituida, sería la clase más avanzada: no en tanto socialista; sería incluso la clase capitalista más avanzada del país.

\section{LA REPETICIÓN TENDENCIAL}

Este decurso nos conduce a ciertos razonamientos adicionales acerca de lo que se puede llamar la materialidad o viabilidad material de un sector social. Se diría que tanto aquellos grupos cuya decadencia comenzó casi de inmediato a su composición (la burocracia), como aquellos de tardía composición, como la burguesía (composición que se infiere de un factor ajeno a ella) y aun los que se planteaban su vida como un proceso de autodeterminación interna y gradual, como el proletariado, todos en conjunto parecían tender a su repetición y, sobre todo, a la repetición intensificada de sus momentos culminantes. Es decir, cuando pensaban en sí mismos recordaban el que fue su momento superior, y aunque no parecían proponerse otra cosa que la reiteración (los militares reaccionarios, como los barrientistas en lo básico, el sistema anterior al 52; la burocracia, el momento semibonapartista, el proletariado, el 52, etcétera), las nuevas condiciones adecuaban su comportamiento de tal manera que, en su aspecto palpable, se hizo algo bastante diferente. Ninguno de esos sectores, en efecto, logró la reproducción de su momento. La burguesía, porque su acumulación, una vez comenzada, tiende a su propia prosecución, o sea que, mientras exista el capitalismo y no se afronten crisis especiales, deberá ser cada vez más poderosa, o sea cada vez más diferente de sí misma, aparte de todo aquello que tenga que ver 
con la reconstrucción de su contorno, etcétera; el proletariado porque, a su turno, consigue su propia agregación clasista y no retrocederá sino excepcionalmente de sus adquisiciones como clase (una adquisición sólo práctica, en todo caso; descubre lo que siempre podía pero, hasta que la clase no lo sabe, es como una potencia encogida. Por eso se llama acumulación de conciencia al descubrimiento o reconocimiento de una posibilidad otorgada por su colocación en el proceso productivo más su devenir subjetivo). Esto es algo así como un cambio hacia adelante; estos grupos no se repiten porque se enriquecen. Pero la burocracia no logra repetirse con éxito porque se empobrece; una vez que ha derrochado la perspectiva de la mediación, que es vista en la etapa semibonapartista como una necesidad por todos, una vez que las puntas se han acostumbrado a vivir sin su intermediación, entonces ya no se funda sino en una memoria o en un propósito estatalista sin mayor envergadura en su impacto sobre los intereses materiales de las clases. Su episodio de retorno tiene por eso esa fragilidad fundamental.

Esto nos ayuda a explicarnos la contradicción entre Bánzer y Ovando-Torres. El ejército tenía el monopolio formal del poder $y$, por tanto, aunque como conjunto representaba al Estado burgués, aunque era de hecho la fase de emergencia del Estado del 52 , en aquello se manifestaba la contradicción entre los sectores militares propiamente estatalistas (porque en este sector se vivía el Estado como un deber patrio), que aspiraban a la reconstrucción de la fase semibonapartista, aunque ésta vivió bajo la hegemonía de la burocracia militar y no de la civil (de la cual, sin embargo, resultaron algo así como un devenir) y los sectores militares que estaban ya incorporados, aun en lo personal o familiar (a través de esta forma constante de acumulación que es la corrupción desde el aparato estatal, muy amplia en los altos mandos a partir de 1964) a la nueva burguesía, y que se proponían acelerar la acumulación capitalista con una dictadura lata sobre las masas, dictadura que, por lo demás, se insertaba mejor con el rush anticomunista que vivía la región geopolítica. 
Así no obstante, esta propia discriminación, que contenía en potencia no sólo la contradicción ejército-ejército, sino también — asimismo en potencia - otra ejército-burguesía, pero, de un modo mucho más inminente, la coincidencia clase obrera-ejército (en lo que se expresa el hecho de que la clase obrera es a la vez la más avanzada clase capitalista y su negadora) y la separación automática entre Estado burgués y clase obrera, es algo que no se incorporaría a la conciencia proletaria sino después de discusiones importantes, sobre todo aquellas que se localizaron en la cuestión del método. De allá resulta el estudio de las otras clases como parte del conocimiento de la propia y la conciencia de que, mientras el campesinado se prepara para nuevos apetitos democrático-burgueses, es decir, para una nueva revolución democrática, el comportamiento de la burocracia estatal, específicamente la militar, tendía a conformar una alianza con el proletariado que duraría hasta el instante mismo en que se tomara el poder; en ese instante, en efecto, la burocracia recordaría su religión estatal y aplicaría la contradicción Estado burgués-proletariado. La formidable conducción obrera en los hechos de octubre de 1970, que dieron lugar al gobierno de Torres, fue la aplicación de sus reglas del conocimiento interclasista en Bolivia.

\section{ESTRATEGIA DE LA BURGUESÍA NACIONAL}

El sector estatalista o progresista o nacionalista del ejército, el sector militar de la burocracia estatal creada por el MNR, se expresaba en el llamado Mandato de las Fuerzas Armadas, con el que subió Ovando y gobernó Torres, y en la llamada Estrategia socio-económica del desarrollo nacional. Puesto que este segundo es uno de los pocos documentos en los que ha habido influencia de las corrientes sociológicas continentales sobre una definición boliviana, vale la pena hacer algún hincapié en él.

Para la Estrategia, 
La dependencia y la marginalidad constituyen los rasgos centrales de nuestra sociedad.

No se trata aquí solamente de la subordinación histórica del país a otros más fuertes, sino que se apunta al hecho de que la estructuración interna de su economía y su vida social y política se deriva básicamente de las formas que asume la dominación. ${ }^{14}$

Se define a la marginalidad como:

[...] el resultado del desarrollo desigual de la sociedad dependiente. Cada una de las grandes etapas de cambio de los países metropolitanos ha generado cambios en la organización de la economía, de la sociedad y del Estado en los países periféricos. Pero como esos cambios no se hicieron para responder a necesidades internas, en los países latinoamericanos se ha producido una situación en la cual se combinan y se integran, en el mismo momento, modos y niveles de producción, de estratificación y de poder político correspondientes a etapas distintas del desarrollo capitalista de los últimos siglos, dando como resultado un proceso de desarrollo desigual y combinado. ${ }^{15}$

Ya aquí podemos esbozar algunas observaciones:

1. El rasgo central de la sociedad no está dado por la dependencia y la marginalidad, sino por la naturaleza de clase de su sistema estatal-económico. Aquí, en cambio, se apunta como carácter principal. Esto mismo de naturaleza de clase, sin embargo, es sólo una manera de aludir a lo que es la fisonomía o el perfil de la formación económico-social, entendida de dos maneras: primero, como un proceso, es decir, como formación económicosocial que atraviesa el tiempo; esto que llamamos hoy formación económico-social boliviana, con sus grandes variaciones espaciales

14 Estrategia socio-económica del desarrollo nacional [1971-1991]. Bolivia, La Paz, Ministerio de Planificación y Coordinación, 1970.

15 Ibid. 
y fisiognómicas, sin embargo, no es algo que nazca junto con el mercado mundial ni aparezca cuando llegan los portadores del mercado mundial; en segundo término, como remate o conclusión de este proceso, caso en el cual, en efecto, nos interesamos en la forma de la unidad, es decir, en el modo de la articulación de aquella desigualdad histórica acumulada. En ambos casos, sin embargo, decir que la marginalidad define al país o que la dependencia es su rasgo central, sería lo mismo que decir que su "rasgo central" es su polilingüismo o su falta de integración nacional, o cualquier otro carácter zonal de una formación que, sin embargo, debe conocerse como conjunto. Vamos a ver después, en la medida en que ello es posible, cómo la propia dependencia está determinada por la sociedad que la recibe, aunque obviamente determinándola a la vez en el grado en que el tipo de recepción lo admite.

2. No es que la lucha de clases dependa del carácter de la dominación, porque en este caso la sociedad dependiente no podría producir sino dependencia indefinidamente, e incluso las propias luchas de los sectores oprimidos no podrían moverse sino en los términos dados por la conservación del sector opresor. La propia dependencia y la dominación en general dependen, por el contrario, del modo de definición interior de la lucha de clases, aunque es obvio que, hasta que no triunfe la línea de liquidación de la dependencia, esto no hace sino condicionar una dependencia que de todas maneras debe suceder. Aquí la externización del análisis tiende a suprimir o disminuir o eufemizar la importancia fundamental de la lucha de clases.

Este defecto del ángulo o perspectiva es algo decisivo dentro de la Estrategia, es decir, en su desvalorización. En la fase que vivimos en Bolivia, por ejemplo, el "rasgo central" está dado por la existencia de la revolución burguesa en el 52, es decir, el tipo de sociedad a que dio lugar. Pero la revolución no fue resultado de la dependencia ni de la marginalidad; por el contrario, existió a pesar de la dependencia y de la marginalidad, existió contra ambas.

3. Tampoco significa nada decir que una sociedad es desigual y combinada. Todas las sociedades en general, incluyendo 
las socialistas, son desiguales y combinadas. Lo que interesa en un análisis es el modo en que se manifiesta la desigualdad y la combinación; desigualdad y combinación que, en efecto, aunque encuadradas, como es natural, por el modo de producción a escala mundial, dependen, sin embargo, tanto del proceso de la formación, es decir, de sus predeterminaciones, como, en lo actual, otra vez, del desarrollo interno de la lucha entre las clases.

4. En cuanto a la marginalidad, el "rasgo central" de Bolivia como país no es la ausencia de las masas sino su espectacular presencia reiterativa, a pesar de sus débiles conexiones con el mercado interno en el juego de la economía (aunque esto mismo - lo del mercadeo - es algo que podría discutirse bastante).

Pensar que "la impermeabilidad e incomunicación entre los diferentes estratos sociales" es parte de ese carácter (el rasgo central), es también ignorar momentos estelares imprescindibles de la historia del país. Lo característico de esta historia, en efecto, es la continua comunicación política entre sus clases, estratos, grupos y segmentos, y eso es lo que explica la insurrección del 52 o los períodos de Ovando y Torres, etcétera.

La evolución de los hechos históricos habla más bien de períodos de incomunicación y de períodos de intensa comunicación, de fases de permeabilidad y fases de impermeabilidad.

5. Aparte de ello, errores de hecho, pero muy abultados. Ejemplos: decir que "el desarrollo del sector minero (como consecuencia de las reformas estructurales, v.gr. la Estrategia) crea condiciones para la organización de la clase obrera", es llanamente falso. Por el contrario, la propia nacionalización de las minas fue un evidente resultado de la organización de la clase obrera.

Lo mismo cuando se dice que "la descomposición de la vieja clase latifundista posibilita una primera movilización del campesinado". Es falso otra vez. Las luchas agrarias en Bolivia son muy antiguas y no se puede suprimir de un plumazo, por ejemplo, la participación campesina en la Guerra Federal de 1899 ni los movimientos mismos posteriores a Villarroel, que fueron parte de la construcción del 52. 
Otro tanto cuando se dice que "la Revolución de 1952 fue encabezada en parte por sectores medios (profesionales, maestros, periodistas, empleados, etcétera)". Aquí hay omisión de la clase obrera, que tuvo un rol aplastantemente superior al de todos los mencionados.

\section{M.P. DE PUNTA, M.P. DE RESABIO}

La Estrategia dice que

[...] para la explicación de la marginalidad económica y social, la dependencia juega un papel central en nuestro país, como en los demás países latinoamericanos, las relaciones de dominación a que históricamente fueron sometidos, se fueron modificando concomitantemente con las transformaciones que ocurrían en las economías de los países desarrollados. Esto significa que, en cada una de las etapas de cambio en las formas de dominación, se han generado transformaciones que ocurrían en las economías de los países desarrollados. Esto significa que, en cada una de las etapas de cambio en las formas de dominación, se han generado transformaciones en las estructuras económicas, sociales y políticas de los países periféricos. Pero como estas transformaciones se realizaron en forma desarticulada, y además como las mismas tuvieron su origen en fenómenos exógenos a los países periféricos, el resultado fue un proceso de desarrollo desigual en los distintos sectores de la economía y en diversas formas de relación social, tanto desde el punto de vista regional como sectorial. Asimismo estas transformaciones no fueron totales en cada etapa. Siempre perduran en los países periféricos vestigios de formas de producción y de relaciones sociales no superadas totalmente. Así se genera una situación en la cual se integran, en el mismo momento histórico, formas y niveles de producción, de estratificación social y de poder político correspondientes a etapas históricas distintas de las relaciones de dependencia. ${ }^{16}$

16 Ibid. 
Esto es verdad en el mismo sentido en que, por ejemplo, la producción prefeudal se volvió marginal con relación a la feudal cuando ella apareció, y está en similar situación respecto de la producción mercantil simple y así con el capitalismo, etcétera. Pero no se dice por qué allá la aparición de un nuevo régimen productivo fue también un modo de disolución del anterior, y por qué eso no ocurre aquí, donde la eternización de las fases predecesoras - en el concepto de la definición que da la Estrategia- parecería ser la regla.

Tal sucede porque se presta una atención sobresaliente al momento de la llegada a la periferia de las fases del capitalismo del país central (cuando la economía mundial ya existe) y no al modo de recepción de esa fase, que es, a juicio nuestro, lo fundamental de esta imbricación, o sea lo que da el tono de un tipo u otro de subdesarrollo. Esto se puede decir de otra manera: lo decisivo no es el modo de producción que se sitúa en la cúspide o punta - lo que de cualquier forma tenía que ocurrir en un mundo que se ha hecho mundial—, sino cuál es el resabio o resaca o supervivencia que impide la plenitud o generalización del desarrollo de ese modo de producción dominante pero no generalizado.

Pero ésta no es la visión que desarrolló la Estrategia. Para ella, lo normal es la fase del país central que llega a la periferia. Dentro de eso, "perduran" los vestigios o hay relaciones "no superadas totalmente", pero como un incidente del episodio central, que es la fase que ha llegado. Perdura mientras no hay progreso, y el progreso las superará. Nos parece que las cosas suceden al revés. Las previsiones de Marx sobre el desarrollo del capitalismo en la India no se cumplieron, y ello no fue fruto de la ineficiencia inglesa sino de los modos de relacionarse que tienen las formaciones económico-sociales que provienen de la fase no mundial de la historia. No sólo que el sector de supervivencia o resabio no es algo simplemente "no superado del todo", sino que determina la posibilidad o potencia del sector de punta. Es el resabio el que impide o mata ad ovo la posibilidad de aparición autónoma de la burguesía como clase, no como supercolocación, sino como nacimiento interno, y es el resabio, por último, el que en general, 
a nuestro modo de ver, define a largo plazo la inviabilidad del desarrollo capitalista de un país como Bolivia.

Nos parece que estamos ante un quid de cuestión. Si la burguesía no tiene aquí un surgimiento original es porque no nace como resultado de la fase autónoma de la formación económicosocial, sino de la fase de la irrupción del centro sobre la parte a la que convertirá en periferia. Aun esto empero con sus propios reparos. Los mismos conquistadores no podían venir sino con lo que eran, es decir, con su propia formación económico-social, que no había completado tampoco su unificación (si es que España la completó jamás), y era ilusorio por tanto pensar siquiera en la uniformidad de una fase de la formación de traslado cuando, además, la propia complejidad española no podía existir aquí ni siquiera con lo que tuviera de feudal, de mercantil o de burgués, omitiendo la resaca o resabio de las propias formaciones precolombinas.

Por otro lado, no solamente este tipo de capitalismo no tiene en los sectores precapitalistas a un enemigo, sino que, por el contrario, en gran medida se funda en la existencia de dichos sectores precapitalistas. ¿Cómo podía, por ejemplo, la oligarquía minera, aquella mínima burguesía de carácter oligárquico, imponerse sobre el poder político de la oligarquía latifundista del sur en la Guerra Federal de principios de siglo, sin apoyarse en el movimiento encabezado por Zárate, el Temible Willka? Por otro lado, ¿podrían el MNR (partido pequeñoburgués portador de los ideales de la nueva burguesía) y el proletariado imponerse sobre el Superestado minero al margen de aquel movimiento campesino en el que se mezclaban la lucha por la división de las haciendas y la reivindicación de las comunidades?

Finalmente, es la misma aplicación de la ley de las formaciones económico-sociales la que permite interpretar la diferencia de desarrollo capitalista entre unas y otras zonas del espacio histórico latinoamericano, y también la desigualdad interna de desarrollo capitalista dentro de las mismas naciones; eso y no la teoría de la dependencia. Si el desarrollo capitalista es más acelerado en el polo oriental de Bolivia (por ejemplo en Santa Cruz), se debe a que allí existen menos resabios que en el sector occidental y, por 
consiguiente, una vez creada una infraestructura mínima, puede desenvolverse sin mayor resistencia. Lo mismo ocurre en el desarrollo comparado de los países latinoamericanos. Aquellos que tienen que afrontar menos resabios son los que están dispuestos para adquirir un mayor desarrollo capitalista. La disposición de buenos recursos naturales o de una población previamente acostumbrada a la producción capitalista pueden ser ventajas, pero no son las decisivas.

¿Qué habrá ocurrido entonces? ¿Se podrá decir que "las transformaciones que ocurrían en las economías de los países desarrollados" llegaban de maneras diferentes a los distintos lugares? Si la determinación mayor viniera de la fase del país central, ¿Cómo es que no somos países uniformes? Pero es, en cambio, el índice de resistencia el que explica que dicho impacto tenga implicaciones en todo diferentes en su comparación entre una formación económico-social y la otra.

Con todo, lo que es un obstáculo para un pleno desarrollo burgués capitalista no lo es para el desarrollo del proletariado ni de su sistema político. Esto es algo que vamos a ver en un momento.

\section{TEORÍA DE LA DEPENDENCIA Y NACIONALISMO REVOLUCIONARIO}

Aun con estas considerables salvedades, la exposición de tal esquema de desarrollo en torno al continuum dependencia-marginalidad no deja de tener sus propios e indiscutibles méritos. En el fondo, ésta fue la "ideología" con la que actuó el sector progresista del ejército y el propio nacionalismo en general. Por cuanto ellos son aliados, ocasionales pero importantísimos, del proletariado, es una posición netamente más progresista que aquella que se tipifica en Bánzer y que expresa la alianza entre la burguesía minero-comercial del altiplano y la burguesía capitalista rural del oriente.

Veamos cómo se produce dicho ensamblamiento. Dice la Estrategia que 
Como los diferentes sectores sociales se vinculan entre sí, los grupos dominantes internos sustituyen a la gran minería y a los latifundios, sin conformar un grupo nacional fuerte y autónomo capaz de constituir un frente con los grupos populares, para hacer viable el proceso revolucionario del $52 .{ }^{17}$

Es decir, debe crearse dicho "grupo nacional fuerte y autónomo capaz de constituir un frente con los grupos populares". Para ello, se deben cumplir los

[...] dos objetivos principales de esta Estrategia: liberación de las estructuras de dependencia y participación popular, que están inseparablemente unidos y se exigen recíprocamente. Para lograr la participación popular en la tarea de liberación y de superación de la marginalidad, debe aprovecharse el dinamismo existente en los grupos populares, reactualizándolos sobre nuevas bases. ${ }^{18}$

Está claro que la participación, término con el que la sociología burguesa sustituye a la movilización de las masas, no puede ser entendida como el acceso de las clases oprimidas no burguesas al poder. Debe, por el contrario, aprovechar su dinamismo, o sea, su actual capacidad de movilización, pero reactualizándola sobre nuevas bases, es decir, con una mediación, una participación condicionada que en el mejor de los casos podía parecerse al momento del reflujo obrero en la fase semibonapartista, pero de ningún modo a la hegemonía de las masas del 52.

Es una exposición franca de la posición de la burocracia militar semibonapartista. Es lógico, por otra parte, que esta corriente preste una atención tan considerable a las tesis dependentistas, puesto que para el nacionalismo revolucionario en general la contradicción entre la nación y el imperialismo se sobrepone a la contradicción interna entre las clases que no son libres sino cuando la nación es libre; una vez que es libre la nación, recién se

$\begin{array}{ll}17 & \text { Ibid. } \\ 18 & \text { Ibid. }\end{array}$ 
puede discutir cuáles son los términos de la libertad de cada una de las clases dentro de la libertad de la nación. La nomenclatura dependentista simplemente dota de nuevos ropajes y apariencias a las doctrinas contenidas, por ejemplo, en Montenegro, sea en Nacionalismo y coloniaje o en Documentos.

\section{LA TESIS DE LA CENTRAL OBRERA BOLIVIANA}

El mencionado renacimiento de las tesis estatalistas y nacionalistas que se expresa en la Estrategia, que en realidad encarnaba el ideario económico-social del rapto militar bonapartista de Ovando, fue replicado por la clase obrera por medio de la Tesis Política de la Central Obrera Boliviana (COB), que se aprobó en mayo de 1970. El hecho de que a las tesis de la Federación de Mineros sucediera ahora una Tesis de la СОВ demuestra que el proletariado minero estaba entonces ya en condiciones de imponer su posición a toda la clase. Se recogen en ese documento las experiencias del 52, es decir, la colocación de la clase frente a un movimiento democrático más extenso que ella, así como la conciencia que se adquiere de la importancia de la democracia como tal para el libre desenvolvimiento de la clase, después del período de Barrientos. Éste, al fundar su gobierno, de corte rotundamente pronorteamericano, en la alianza entre los sectores conservadores del ejército y el campesinado ligado al nuevo sistema estatal, había concentrado la acción violenta del aparato represivo sobre la clase obrera. El resultado de ello fueron las mantanzas de 1965, en la mayor parte de los distritos mineros, y la que ocurrió en 1967 en Catavi, aparte del encarcelamiento y la prisión de los dirigentes sindicales de algún relieve.

En primer término, en esta Tesis figura la descalificación de un proceso revolucionario que tenga en su dirección a una clase no proletaria y su necesaria frustración:

La historia enseña que en la presente etapa en que se desintegra la dominación imperialista, los países atrasados alcanzarán la meta de la civilización, vale decir, del desarrollo integral y armónico, sola- 
mente por la vía socialista. Las tareas democráticas, que ciertamente no pueden ser ignoradas, para realizarse en forma plena precisan que el proletariado se convierta en dueño del poder político, como portavoz de la nación oprimida, de nuestros hermanos campesinos y de la población pobre de las ciudades [...] El proceso de tipo democrático burgués que estamos viviendo no tiene posibilidades de mantenerse indefinidamente como tal. Se transforma en socialista mediante la toma del poder por la clase obrera o fracasa. ${ }^{19}$

Por otra parte, un rechazo específico de las postulaciones contenidas en la Estrategia del desarrollo económico social, a que nos hemos referido en las páginas anteriores:

El nacionalismo burgués o pequeñoburgués busca consumar una serie de reformas estructurales, o sea, pretende superar las formas de producción precapitalistas con la finalidad primordial de modernizar el país, abrir campo a las inversiones foráneas, al capital financiero y mantener indefinidamente el régimen capitalista. El desarrollo estilo CEPAL, los programas de nacionalizaciones y los tímidos intentos de planificar algunos sectores de la economía no tienen más que ese sentido. ${ }^{20}$

Sobre el nacionalismo militar:

De una manera general, los gobiernos militares nacionalistas aparecen en el escenario debido a la inoperancia y el fracaso político de la burguesía, como carta sustituta para consumar la transformación capitalista indicada más arriba. Es claro que el ejército a su izquierda (porque también existe este fenómeno) es producto de la clase dominante de las peculiaridades nacionales, y por eso mismo lleva indelebles los rasgos de las limitaciones y la impotencia propias de las burguesías nacionales de la época actual. ${ }^{21}$

\footnotetext{
19 Tesis política de la Central Obrera Boliviana (COB), La Paz, 6 de mayo de 1970.

20 Ibid.

21 Ibid.
} 
Una recapitulación de la posición obrera frente a los anteriores gobiernos nacionalistas:

Declaramos los trabajadores que en su momento apoyamos a dichos gobiernos ya señalados (los nacionalistas). Los apoyamos no desde el punto de vista puramente lírico, sino con una activa militancia revolucionaria. Sin embargo, fueron estos gobiernos, a pesar de todo, los primeros en abandonar su pose antiimperialista y en concluir como enemigos de la clase obrera y del pueblo [...]

El proceso democrático se estancó en sus albores y, luego, caímos en un mayor predominio del imperialismo, comprobamos, en carne propia, que los procesos democráticos y nacionalistas que no son dirigidos por el proletariado y transformados en un proceso socialista, concluyen siempre en la frustración y la derrota. ${ }^{22}$

Sobre la independencia de clase:

Nuestra posición frente a los procesos democráticos dirigidos por la pequeña burguesía no es otra que mantener nuestra independencia de clase, desde el momento en que dichos procesos no resuelven el problema nacional y menos las contradicciones de nuestra sociedad. La táctica de la clase obrera es entroncarlos en la estrategia final del socialismo. Nuestro objetivo es el socialismo y nuestro método para alcanzar dicha finalidad histórica es la revolución social que nos permitirá transformar el proceso nacionalista en socialista. ${ }^{23}$

Sobre el capitalismo de Estado:

Para nosotros los trabajadores la lucha antiimperialista tiene un solo contenido: la lucha por el socialismo. Están equivocados aquellos que se afanan por darle otro contenido. Diariamente se viene especulando que el nacionalismo es ajeno tanto al capitalismo clásico como al socialismo. Se insinúa que una política neutra entre ambos

22 Ibid.

23 Ibid. 
extremos, que llega a su punto culminante bajo la forma de capitalismo de Estado [...] algunos teóricos de esta tendencia sostienen que la América Latina puede lograr su pleno desarrollo económico siguiendo el "modelo nacional del capitalismo de Estado", por conciliación entre el capital privado con la economía estatal. Ambas formas de economía, al no salir del área del sistema capitalista, concluyen consolidando nuestro atraso y dependencia [...]

No debemos olvidar que Bolivia es, fundamentalmente, un país atrasado. Y es atrasado porque continúan pendientes de realización ciertas tareas democrático-burguesas. Por tal razón, está cerrada toda posibilidad de desarrollo económico integral dentro de las formas de una economía capitalista, sea ésta privada o estatal, o la llamada "concertación" de ambas, mientras no se rompa definitivamente con el imperialismo. ${ }^{24}$

Sobre la hegemonía del proletariado y su sistema de alianzas:

La experiencia de 1952-1964 nos enseña que una revolución, para ser victoriosa, no debe detenerse sino continuar hasta el fin, y que el problema decisivo es la cuestión de saber qué clase controla el poder. No basta la acción insurgente de las masas sino definir quién asume la dirección de esa insurgencia. No basta la participación heroica de la clase obrera en los acontecimientos del país, sino la forma que asume esa participación y si ella actúa en pos de sus propios objetivos. Es preciso, en fin, que conquiste el rol hegemónico en el curso de la lucha, atrayendo hacia su lado a las masas campesinas y a los amplios sectores urbanos [...] El problema que se le plantea al proletariado boliviano es el de constituirse en una poderosa fuerza social y política independiente y actuar dentro de la apertura nacionalista y democrática para conquistar el poder. En este sentido, los trabajadores rechazamos toda posibilidad de volver a la experiencia negativa del llamado "cogobierno", que cerró el camino de la clase obrera a la conquista de todo el poder y que, al haberse convertido en un instrumento de control y freno de la

24 Ibid. 
pequeña burguesía sobre los trabajadores, terminó en el mayor de los desprestigios por la traición que significó al rol histórico del movimiento obrero. ${ }^{25}$

\section{LA ASAMBLEA POPULAR}

Es sobre la base de esta Tesis que se constituye en 1971, durante el gobierno de Torres, la Asamblea Popular. La Asamblea misma fue una evolución orgánica del Comando Político de la clase obrera, que dirigió la huelga de masas que impuso el triunfo de Torres, su contragolpe, frustrando el golpe derechista del sector reaccionario del ejército en octubre de 1970. La clase obrera no se entregó entonces a un abstracto antigolpismo: posibilitó el éxito del sector democrático del ejército, pero en lugar de incorporarse a él, se abocó a la organización de su propio poder.

¿Cómo se definió a sí misma la Asamblea Popular? En su Estatuto dice: "La Asamblea Popular es un frente revolucionario antiimperialista dirigido por el proletariado".

Luego, explícitamente:

Reconoce como su dirección política al proletariado y declara que su programa es la Tesis Política aprobada por el IV Congreso de la Central Obrera Boliviana, realizado en mayo de 1970.

La representación proletaria será indefectiblemente el 60\% del total para efectivizar su dirección política dentro del frente antiimperialista. ${ }^{26}$

No pueden participar en la Asamblea todos los partidos, sino aquellos que suscriban la Tesis de la COB y que tengan antecedentes no contrarios a la clase obrera.

En las bases de Constitución, se dice que

25 Ibid.

26 Asamblea Popular, Estatuto, 1 de mayo de 1971. 
Hay que recoger una experiencia que confirma a plenitud la teoría y que debe desarrollarse: el funcionamiento de la $\mathrm{COB}$ como asamblea popular después del 9 de abril de 1952. En los hechos se erigió en un poder real y no legal. Obligó al Gobierno a dictar las medidas reclamadas por las masas populares. El poder de la clase obrera y las organizaciones profesionales y políticas representó en ese breve período la fuerza concentrada del proletariado, cuya primacía sobre los demás sectores se manifestó en la acción ejecutiva propia, sin acondicionarse al gobierno de la Nación. Por tanto, la Asamblea Popular debe expresar, en lo fundamental, los intereses del pueblo dirigido por la clase obrera. ${ }^{27}$

Aquí, naturalmente, se nota una clara conciencia del carácter estatal que tiene la Asamblea, lo cual se ve confirmado en el párrafo que habla de que

[...] aún no actuamos en una revolución social, pero el período de transición de la época actual, principalmente en nuestro país, induce a conformar órganos del gobierno central que constituyan la expresión de una política propia y de concentración de fuerzas que asignen a la Asamblea la verdadera calidad de poder dual. ${ }^{28}$

Pero la Asamblea no es tampoco una negación a secas de toda la política del gobierno democrático:

El carácter independiente no supone prescindencia o neutralidad, desde que la Asamblea Popular, al luchar por la liberación nacional, sostendrá las medidas revolucionarias, actuará conjuntamente con el Ejecutivo contra el fascismo y el imperialismo o alternativamente se pondrá frente al Gobierno cuando las medidas de éste atenten contra los intereses del pueblo y se aparten del proceso. ${ }^{29}$

$\begin{array}{ll}27 & \text { Ibid. } \\ 28 & \text { Ibid. } \\ 29 & \text { Ibid. }\end{array}$ 
Éstas son las bases teóricas y las enunciaciones de la Asamblea Popular. Veamos ahora su índice de eficacia histórica y sus obstáculos.

La Asamblea era obrerista; pero eso no era sino literatura, puesto que no era eficaz en la misma medida en que era obrerista. Ahora bien, el sobredesarrollo de las corrientes sindicalistas con la política boliviana es algo que resulta de la historia del movimiento popular; no es una mera forma: es como si estuviera dentro de él. Es verdad (ésta es una correcta apreciación de Guillermo Lora) que los obreros bolivianos casi nunca concibieron el sindicato como un mero sindicato. En los grandes momentos sobre todo, las organizaciones obreras funcionan como una suerte de soviets, asumiendo tareas que corresponden al Estado.

Incluso cuando existe el doble poder, en 1952, no se habla en él del poder obrero (es decir, de la ideología proletaria encarnada en el partido obrero) a un costado y del poder burgués al otro. Se habla, en cambio, de la $\mathrm{COB}$ —es decir, la organización sindical-y del partido democrático-burgués, como si los sindicatos hubieran ocupado el papel del partido bolchevique.

En el ascenso de las masas, tal como sucedió en Bolivia, los sindicatos son determinantes, pero en cambio los partidos no lo son en los sindicatos. La FSTMB, por ejemplo, siempre fue más importante y poderosa que los propios partidos a que pertenecían sus integrantes. El sindicalismo sobrevive a todas las persecuciones, pero, en contraste, ningún partido logra reemplazar al MNR en el control de los sindicatos, control que, además, el MNR perdió muy temprano. Hay pues una hipertrofia en el papel de los sindicatos que caracteriza a todo el proceso histórico boliviano.

Es un fenómeno que también se manifestó en la Asamblea Popular, incluso en sus requisitos estatutarios.

Era correcto, para mencionar un caso, establecer un predominio proletario, es decir, una superioridad cualitativa sobre la cantidad del proceso, que eran los campesinos, clase burocrática, dependiente y osificada en la conquista democrático-burguesa de 
la tierra. Esto significaba que no se elegía un proceso democrático-formal, sino que se pensaba en efecto en la construcción de la dictadura del proletariado como definición del doble poder. Pero si esto era un soviet, era un soviet sin el partido de la clase obrera, y así, en lugar de que triunfara la ideología proletaria en manos del partido revolucionario, triunfó la línea sindicalista, que sólo a medias respondía a los partidos. Los dirigentes sindicales, $v$. gr., pertenecían a partidos que votaron contra Lechín; pero ellos mismos votaron por Lechín, porque era miembro de la Federación y ésta lo había resuelto así.

La confusión entre lo que es la ideología proletaria, la posición obrera y la condición obrera se mostró típicamente. Se daba más importancia a la extracción de clase y aun al origen de clase (condición obrera) que a la ideología del proletariado y, en todo caso, la posición obrera (es decir, la posición de esa clase obrera en coyuntura) dio un matiz sindicalista a la Asamblea. Por esta vía, se puede decir que la Asamblea Popular fue la fase más alta del proceso populista de las masas bolivianas, en lugar de ser el primer órgano de poder de la revolución socialista.

Veamos también otro aspecto que puede llamarse el de la no correspondencia entre las organizaciones y el movimiento de bienes.

Los mineros habían entrado en la política en la década de los cuarenta. Fue el MNR quien los introdujo, y también el que metió en la política a los campesinos en la década de los cincuenta. Hasta entonces, ambos sectores no existían para los fines de la política, sino por irrupciones. La política se definía en el margen correspondiente a las capas urbanas intermedias. Por eso el MNR pudo desarrollarse como un auténtico partido de masas. El MNR dio a las masas su carácter (pequeñoburgués, nacionalista, populista), y las masas dieron su carácter al MNR, que se amoldó a ellas a lo largo del tiempo; fue un partido radical cuando las masas eran radicales (en el 52); cuando las propias reformas demoburguesas despertaron sentimientos conservadores en ciertos sectores de las masas, como los campesinos, el MNR se hizo conservador. Aquí corresponde una digresión, para el buen desarrollo del asunto. Es el problema de la relación entre las masas y los partidos de la 
izquierda. La movilización de las masas, ¿se desprendía de los partidos, había sido organizada por ellos o, por el contrario, los partidos de izquierda se beneficiaban, en la negociación política, con un ascenso de masas previo a ellos?

El populismo es la forma en que existieron las masas de Bolivia, y el espontaneísmo su método, el MNR su partido, Lechín su jefe sindical. Naturalmente, el populismo ya fracasó como fórmula de poder en 1964, el espontaneísmo ha sido vencido cuantas veces ha sido necesario por el ejército, el MNR no vino a ser sino un harapo de lo que fue, y Lechín no sobrevivía en el momento de la Asamblea sino en la medida en que se amoldaba a los hechos, casi como una costumbre de los sindicatos. Pero cuando Ovando abrió las compuertas que contenían a las masas, cuando dejó el barrientismo, las masas existieron de la única manera que sabían existir: espontáneamente. Esto puede decirse de otra manera: las masas se movilizaban hacia un lado y los partidos hacia otro; los partidos eran como parásitos de una movilización de masas que no les pertenecían; trataban de explotar ese movimiento pero, en definitiva, no lo conducían y, por el contrario, acabaron por seguirlo. Aquí sí, como dijo Lenin de 1905, "Las organizaciones habían quedado atrás respecto al crecimiento y la envergadura del movimiento".

¿Cómo eran, por ejemplo, las masas obreras en ese momento? Eran populistas; su dirección ya no lo era y sus dirigentes eran lo mejor que había en toda la política del país. Pero las masas mismas, por su visión de la política, por sus hábitos, por sus propósitos, son populistas. Su punto de decisión política era la asamblea, como la plaza del pueblo entre los campesinos, pero no el partido. La propia Asamblea Popular, al exacerbar el acento en la consideración del concepto de la condición obrera, al hiperbolizar la extracción de clase y la ideología de clase, era una institución que seguía las inclinaciones auténticas de las masas, su patriotismo obrerista, pero sin organizarlos para llegar a un grado político superior. Es una realidad desgraciada: la deserción del MNR corroboró el defecto de las masas bolivianas, que es la desviación sindicalista. Cuando el ascenso de masas es expresa- 
do sólo por un instante por un partido que no asume el carácter final de dicho ascenso o no puede cumplir las tareas que le pide, se puede decir que la historia sucede de una mala manera.

Aun en esas condiciones, sin embargo, la Asamblea fue la más avanzada expresión del poder obrero, una experiencia que no había existido jamás en parte alguna de América Latina. Hay que preguntarse por qué el proletariado fue súbitamente poderoso el 7 de octubre y cómo fue tan débil políticamente durante el barrientismo. Las cosas se presentan como si no fueran una misma clase, sino dos clases distintas; tanta es la diferencia entre un momento y el otro. Es, otra vez, algo que resulta no de su colocación en el proceso de la producción, que es el mismo en un momento y en el otro, sino de un devenir interno como clase y, aún más que eso, de su acumulación como acontecimientos, es decir, de su historia en cuanto clase, que es lo que le da lo que se puede llamar un modo de ser. Está a la vista que la clase tiene flujos y reflujos, que su comportamiento es distinto en situaciones distintas; pero es básicamente una clase victoriosa y tiene un ánimo ofensivo. En una misma colocación estructural, una clase puede, en efecto, desarrollar una distinta personalidad según el grado de éxito que tenga en su táctica, en el azar de sus dirigentes, en la fortuna de sus operaciones. ¿Cómo era que esta clase, que imponía la ley a todas las demás, que tuvo en el 52 un poder tan inmenso como para liberar a otra clase, la más extensa, un poder, convengamos, más grande que su propia madurez, sin embargo no pudo organizar, en mayo del 65, la mínima resistencia ante la ofensiva de la Restauración? ¿Y cómo ahora, en octubre del 70, podría otra vez obligar a un gobierno a aceptar formas así sea nacientes de un poder dual, en una suerte de esfuerzo de restablecimiento del estatus histórico del 52 ?

Estos hechos tienen una relación o dependencia respecto de lo que ocurrió en Ñancahuazu en 1967 y en Teoponte en 1969. En ambos casos se verá hasta qué punto el aislamiento del proletariado conduce, al contrario de lo que podría suponerse, a una pérdida en su carácter, de qué manera su verdadero tempo 
no se realiza sino en conexión con las otras clases, cómo, para el proletariado, la posición natural es la de dirigir al frente de clases oprimidas y no el aislarse de ellas. En ambos casos, en efecto, en Nancahuazu y Teoponte, se intenta la instalación de focos guerrilleros; en ambos casos, el ejército reprime salvajemente a la guerrilla y la extermina. La guerrilla no consigue sobrevivir; tampoco logra, por consiguiente, su expansión política hacia las masas. Sencillamente, no tiene tiempo para hacerlo, es vencida en su fase primera. Pero una cosa es el fracaso militar y otra el fracaso político, y aun es posible un fracaso político inicial, localizado, y un éxito político diferido, difuso. Las repercusiones de las experiencias guerrilleras en la formación política del país serían inmensas, en efecto, y la guerrilla tendría arraigo allí donde no se lo proponía o donde se lo proponía menos. ¿Qué quiere el foco guerrillero en materia de movilización política? Quiere la actividad, el respaldo y la conciencia de los campesinos, inicialmente los del lugar donde se desarrolla. Pero el campesinado había creado en Bolivia una relación de dependencia no respecto a la clase obrera, que lo liberó realmente desde el Estado del 52, sino respecto al aparato estatal como tal, es decir, con relación a la máquina estatal desde la que ya formalmente se hizo la liberación. Se dice por eso que es una clase funcionaria: cree en cualquier poder que le respalde la posesión de la tierra, que ha sido su objetivo político secular, su programa único y su identificación. He aquí cómo el precoz desarrollo democrático-burgués expandió el elemento humano de asiento del Estado que estaba creando. Pero lo de Ñancahuazu y Teoponte se afincó en el corazón de las pequeñas capas medias, que era la juventud pequeñoburguesa de las universidades y colegios.

Con este fundamento, las masas se movilizaron en tiempo de Torres con cierta eficacia, puesto que para ello les habilitaba la ruptura del aislamiento obrero, y con ciertas flaquezas, porque no lograban vencer del todo las endebleces de su pasado. No renunciaron a ellas, ciertamente; en alguna medida, las desarrollaron. La Asamblea fue — de algún modo- el desarrollo culmi- 
nante de las desviaciones esenciales del proceso revolucionario boliviano.

La ausencia o vacío que explica esa distorsión es la falta de la existencia de los partidos obreros, o, si se quiere, la existencia insuficiente de los partidos obreros. El MNR no fue jamás el partido de la clase obrera. La clase obrera militó en su seno casi en su totalidad, en determinado momento, pero eso no quería decir que fuera el partido de la clase obrera. No era un partido marxista-leninnista ni era el partido de una clase, sino la alianza de varias clases bajo la hegemonía ideológica y práctica de la pequeña burguesía. Pero era el partido debajo del cual, y en cuyo nombre, se produjo el ingreso del proletariado a la política, su manifestación superestructural. En este sentido, era el partido al que la clase obrera se refería en aquel momento de su desarrollo.

Cuando el MNR fracasó en su intento de hacer una revolución democrático-burguesa dentro del cuadro de la dominación imperialista, cuando se frustró la expansión económica e institucional que se procuraba desde dentro del capitalismo dependiente, se produjo una pérdida o desgarramiento. La clase obrera dejó de tener un punto político de referencia, por lo menos uno que tuviera la eficiencia y la extensión del MNR. En un esfuerzo, que no era consciente, el movimiento de masas intentó reemplazar al partido en el seno del sindicalismo mismo; nadie lo decía, pero allí operaba, en los hechos, cierta oscura convicción de que la diferencia entre sindicato y partido no estaba sino en la amplitud de su propósito, que el partido era como un sindicato más avanzado y que, por consiguiente, el sindicato podía atribuirse históricamente el papel del partido. Pero esto, que operaba en los hechos tanto como se enmudecía a sabiendas en las discusiones, a la vez que acentuó la deformación del proceso, resultó largamente insuficiente. La Asamblea Popular intentó reemplazar ese vacío en la conducción de las masas, porque otra vez de un modo heterodoxo impuesto por la realidad de la situación era como si los soviets hubieran estado compuestos en Rusia mayoritariamente por los sindicatos. Quería ser el instrumento político del movimiento sindical, instrumento todavía sindical en lo básico (porque 
se fundaba en la extracción de clase), aunque con la participación de los partidos de izquierda (que prestan más importancia a la ideología de clase, o deberían hacer tal). Pero la Asamblea no tenía tiempo para lograr su extensión; apenas si existió lo suficiente para decir que existió. Lo preocupante de su programa, y no de su existencia, era parte de la inoperancia obligatoria que resultaba de su conformación sindicalista.

La preocupación porque la Asamblea existiera, en lugar de conformarse con que la $\mathrm{COB}$ asumiera la representación política de la izquierda, como ocurrió en el 52, demuestra ya hacia dónde iba la conciencia de la izquierda. Estaba claro que Bolivia tenía un poderoso movimiento de masas que, por las modalidades de su desarrollo, intentaba con grandes dificultades crear a posteriori una vanguardia política (por una vía ecléctica, no ortodoxa), casi contrariando el decurso normal del crecimiento político, en el que la vanguardia debe crecer junto al movimiento, impulsándolo, corrigiéndolo y siguiéndolo. La prueba de que esta carencia estaba en la conciencia de la izquierda es que la Asamblea existió; la prueba de que no existió en el grado suficiente es que el predominio sindicalista era todavía un requisito estatutario.

\section{AlgunAS CONCLUSIONES}

En todo caso, cualquiera que fuera la debilidad interna de la Asamblea, estaba claro que se trataba de una avanzada clase obrera y que los propios problemas teóricos que proponía eran de una importancia singular. Ahora bien, un pensamiento sociológico marxista no puede surgir con verdadera fuerza sino allí donde hay a la vez un poderoso movimiento obrero. Es un pendant necesario: donde no hay pensamiento obrero, el impulso espontáneo de la clase se interrumpe. Donde no hay impulso espontáneo, la sociología marxista se vuelve ciencia pura, y ya no es marxista. Es el tipo de problemas que va planteando la clase en su desarrollo lo que da lugar al pensamiento marxista.

Si "las ideas de la clase dominante son las ideas dominantes de cada época”, es evidente que la burguesía, que aun en su for- 
ma secundaria no hace sino acabar de constituirse en Bolivia, no es una clase realmente dominante. La difusión del pensamiento marxista tiene tal extensión en el país que, desde 1952 hasta hoy, ningún gobierno se atreve a excluirlo, por ejemplo en los sindicatos o en las universidades, por lo menos en su uso terminológico. Las mismas ideas que la burguesía expone son aquellas que supone que pueden ser aceptadas por el movimiento obrero. El proletariado, sin embargo, no ingresa en la política real del país sino en la década de los cuarenta y, aunque adquiere un crecimiento fulminante, no hay duda de que se trata de una clase joven. Los obstáculos que le impiden tomar el poder, incluso cuando se configura como la clase materialmente vencedora, son entonces los que se derivan de su propio desarrollo interno.

Aquí nos topamos con la cuestión de la adecuación o asimilación. Aunque el proletariado es en Bolivia mucho más proletario que la burguesía como burguesía, por las razones dichas, sin embargo carga también con las derivaciones de su participación subordinada en una gran revolución democrático-burguesa y, en general, debe decirse que sólo sus sectores avanzados son hoy clase para sí; la clase en su conjunto es también una clase inconclusa. Ha dejado de ser ya una clase en sí, pero no ha llegado todavía en bulto a ser una clase para sí.

Desde el momento de la transposición escolástica y elemental de las ideas marxistas hasta hoy, la experiencia teórica del proletariado boliviano ha recorrido mucho trecho. Sin embargo, si la asimilación se produjera sólo por la vía del estudio del marxismo, los grados de inmadurez que el proletariado detecta en cada una de sus derrotas serían sólo consecuencia de la falta de lecturas de los intelectuales de la clase obrera.

Es algo que poco tiene que ver con el promedio general del nivel cultural de un país. Sea bajo o alto dicho promedio cultural abstracto, una clase se plantea los problemas que le ocurren. Por eso, el socialismo científico le sirve de fuente indispensable, pero la adecuación de la tesis general y universal a la táctica inmediata es algo que no se puede aprehender sino en las discusiones in- 
ternas de la clase, en su crítica a las posiciones emitidas desde las otras clases y en su invasión práctica a las clases que debe someter.

Un país atrasado puede producir una avanzada clase obrera y, por el contrario, los países avanzados suelen implantar mecanismos de alienación y aristocratización eficientes como para impedir el desarrollo de su clase obrera. Éstos son supuestos que hay que tener en cuenta en todo debate sociológico en torno de Bolivia.

El proceso de integración de la clase obrera en Bolivia puede distinguirse a través de tres etapas:

1. La etapa del espontaneísmo de clase. En este momento, el carácter espontáneo del movimiento obrero es lo predominante de un modo casi absoluto. Dura desde 1940 hasta 1952, por lo menos, aunque sus resabios son por demás considerables en todo lo posterior. El carácter meramente espontáneo de esta etapa no podría sino servir a las modalidades populistas del MNR, cuya principal figura obrera fue Juan Lechín.

2. Es obvio que movimientos verdaderamente espontáneos no ocurren sino por excepción. Por tanto, cuando se habla de espontaneísmo se hace alusión a un carácter dominante. Ha habido antes una distribución molecular de la agitación, que es un riesgo ideológico y, por otra parte, tampoco es imposible adoptar al propio espontaneísmo como un pensamiento, una manera de concebir la actuación de las masas en el momento revolucionario. La descripción del movimiento espontáneo como un carácter esencial del proceso revolucionario puede ser una teoría; de otra manera, no habrían existido Rosa Luxemburgo ni el primer Trotsky.

3. El momento de la construcción del partido de la clase obrera. Lo importante en este campo no es tener en abstracto la idea de la necesidad del partido, sino que ella sea una necesidad conscientemente apetecida por la clase. Es verdad que los partidos marxistas existen desde hace varias décadas; pero sólo adquieren un contenido importante cuando los obreros abandonan el 
populismo, que ya ha defeccionado, sufren nuevos fracasos en la reiteración de sus incursiones de tinte espontáneo, y, en cambio, logran éxitos inusitados allí donde la conducción es llevada por los partidos obreros, como ocurrió en la transformación democrática del régimen de Torres y en la construcción de la Asamblea Popular, aunque cargando con el peso de la tradición anterior.

De cualquier forma, el concepto fundamental que se deriva de las discusiones en la clase obrera boliviana es el de la acumulación en el seno de la clase. Esto tiene derivaciones importantes y se refiere de hecho a los métodos de la clase obrera. La propia aseveración de que la clase no excluye ningún método y de que no se liga tampoco a ninguno en especial, de que la transferencia del método y el repliegue desde el método son opciones propias del partido y no de la agrupación elemental, en fin, todo ello, no halla su implantación sino en la lucha teórica con los sectores que penetran en la discusión obrera ya comprometidos con métodos específicos, como es el caso de los grupos maoístas y los vanguardistas en general. La experiencia guerrillera del 67, en la que murió el comandante Guevara, fue uno de los acontecimientosfuente de esta discusión.

Con todo, se distingue entre lo que son métodos de lucha y método de conocimiento. Para lo segundo se parte, como es elemental en el marxismo, del análisis de las situaciones concretas desde el punto de vista de la composición de clase de la situación y, aunque esto no es para nada una novedad para un sociólogo profesional, sí lo es como práctica intelectual en manos de una dirección obrera; por consiguiente, las cuestiones no ligadas al devenir de la clase se vuelven librescas y la clase no las adopta.

Si se analiza la actuación de los obreros en el momento de la Asamblea Popular o las huelgas generales organizadas por los fabriles en medio de la represión más extensa, en 1972, o la huelga campesina de Cochabamba de 1974, está claro que nada de eso habría sido posible si la masa no hubiera tenido ciertos métodos incorporados así, es decir, si no se hubiera producido esto que llamamos la acumulación en el seno de la clase. Pero, en cambio, 
los intentos de implantación de focos guerrilleros en Nancahuazu y Teoponte, o la débil experiencia de enfoque maoísta en Santa Cruz, en 1971, demuestran que no se trataba de métodos no incorporados.

En cambio, de las experiencias de 1952 y 1971 surge ya la elaboración en principio de una teoría del Estado de la clase obrera, sobre todo a partir de las discusiones acerca del poder dual que, a escala latinoamericana, fueron prácticamente exclusivas de Bolivia, aparte de algún planteamiento lateral en Chile. Pero no hay duda de que es en Bolivia donde las discusiones en torno del tema adquieren una real envergadura.

He aquí, por último, una lista de los temas que han sido discutidos por el movimiento obrero boliviano y que se pueden exponer en este trabajo:

1. Teoría de la crisis nacional general.

2. La acumulación en el seno de la clase.

3. Problemas de la mutación en el seno de la revolución ininterrumpida.

4. Sobre la cuestión nacional en un país atrasado.

5. Estructuras del cambio del poder político en la fase no proletaria.

6. Relación clase-partido-Estado.

7. La irradiación de clase. Problemas que emergen de la expansión de la clase obrera.

8. Discusión sobre el sujeto del poder político en las revoluciones democráticas avanzadas.

9. El carácter de la revolución en Bolivia.

10. Sobre las alianzas. Diferenciación campesina, la lucha democrática por la influencia en los sectores intermedios.

11. Condiciones tácticas de la explotación de las divisiones interburguesas.

12. Carácter del partido en países atrasados con procesos democrático-burgueses esporádicos.

13.La teoría de la semicolonia aplicada a la experiencia nacional. 
14. Problemas del reconocimiento interno de la clase y las regresiones en el movimiento obrero.

15.La cuestión de los métodos. 